\title{
Cooking and co-ingested polyphenols reduce in vitro methylmercury bioaccessibility from fish and may alter exposure in humans
}

\author{
Catherine Girard ${ }^{a}$, Tania Charette ${ }^{b, c}$, Maxime Leclerc ${ }^{b, c}$, B. Jesse Shapiro ${ }^{c}$, Marc Amyot $^{a, b, c}$
}

a. Center for Northern Studies (CEN), Département de sciences biologiques, Université de Montréal, 90 Vincent-d'Indy, Montreal, H2V2S9, Canada.

b. ÉcoLac, Département de sciences biologiques, Université de Montréal, 90 Vincentd'Indy, Montreal, H2V2S9, Canada.

c. Groupe de recherche interuniversitaire en limnologie et en environnement aquatique (GRIL), Département de sciences biologiques, Université de Montréal, 90 Vincent-d'Indy, Montreal, H2V2S9, Canada.

\#Address correspondence to Marc Amyot, m.amyot@umontreal.ca, 514-343-7496. Université de Montréal, Département de sciences biologiques. Pavillon Marie-Victorin, C.P. 6128, succ Centre-ville, Montreal (Quebec) H3C3J7 Canada.

Running title

$\mathrm{MeHg}$ bioaccessibility is reduced by food preparation

\section{Acknowledgments}

The authors thank Dominic Bélanger, Shirley Atoche, Fei Tao Zhou, Valérie de Munck and Mélissande Gaucher for assistance in the laboratory, and Antoine Caron and Maikel Rosabal for advice. Research was funded through NSERC Discovery grant (217099-2012) and the Canada Research Chair program (950-230679) to MA. Student funding was provided by FRQNT and NSERC doctoral scholarships to CG.

\section{Competing financial interests}

All authors declare they have no actual or potential competing financial interest.

\section{Key Words}

Methylmercury, bioaccessibility, cooking, polyphenols, tea, risk assessment 


\section{Abstract}

Fish consumption is a major pathway for mercury exposure in humans. Current guidelines and risk assessments assume that $100 \%$ of methylmercury (MeHg) in fish is absorbed by the human body after ingestion. However, a growing body of literature suggests that this absorption rate may be overestimated. We used an in vitro digestion method to measure MeHg bioaccessibility in commercially-purchased fish, and investigated the effects of dietary practices on $\mathrm{MeHg}$ bioaccessibility. Cooking had the greatest effect, decreasing bioaccessibility on average to 12.5 $\pm 5.6 \%$. Polyphenol-rich beverages also significantly reduced bioaccessibility to $22.7 \pm 3.8 \%$ and $28.6 \pm 13.9 \%$, for green and black tea respectively. We confirmed the suspected role of polyphenols in tea as being a driver of MeHg's reduced bioaccessibility, and found that epicatechin, epigallocatechin gallate, rutin and cafeic acid could individually decrease $\mathrm{MeHg}$ bioaccessibility by up to $55 \%$. When both cooking and polyphenol-rich beverage treatments were combined, only $1 \%$ of $\mathrm{MeHg}$ remained bioaccessible. These results call for in vivo validation, and suggest that dietary practices should be considered when setting consumer guidelines for MeHg. More realistic risk assessments could promote consumption of fish as a source of fatty acids, which can play a protective role against cardiovascular disease. 


\section{Introduction}

A large proportion of the world's population depends on fish. Indeed, fish are estimated to provide $17 \%$ of animal proteins consumed by humans (and $6.7 \%$ of all proteins consumed worldwide) (Food and Agriculture Organization, 2016), and are an important source of vitamins, minerals and fatty acids, which can protect from cardiovascular disease (Mahaffey et al., 2011). However, fish consumption is one of the major pathways of human exposure to mercury $(\mathrm{Hg})$ (Committee on Toxicological Effects of Methylmercury, National Research Council of the United States, 2010), which in its organic form of methylmercury ( $\mathrm{MeHg}$ ) is a potent neurotoxin (Clarkson and Magos, 2008). To protect at-risk populations, $\mathrm{Hg}$ blood guidelines have been established, derived from large-scale studies defining lowest adverse effect doses (Chapman and Chan, 2000; Legrand et al., 2010).

However, there is also a growing body of evidence suggesting that our understanding of $\mathrm{Hg}$ absorption in the body is incomplete. Current recommendations on fish consumption consider that the ingested dose of $\mathrm{Hg}$ from fish is equal to MeHg's - this assumes that $100 \%$ of $\mathrm{Hg}$ in fish is in the form of $\mathrm{MeHg}$, and that MeHg's absorption rate is of $100 \%$ (Committee on Toxicological Effects of Methylmercury, National Research Council of the United States, 2010; Ha et al., 2016). This stems from older studies performed on human volunteers (Aberg et al., 1969) and on rats (Miettinen et al., 1971) with methylmercuric nitrate $\left(\mathrm{MeHgNO}_{3}\right)$. However, this may not be representative of $\mathrm{MeHg}$ speciation in fish, which is more likely bound to thiol groups included in proteins (Clarkson and Magos, 2008; Harris, 2003). Indeed, assuming that nearly all of $\mathrm{Hg}$ in fish is bioavailable may overestimate intake by $50 \%$ (Ha et al., 2016): while the absorption rate of solubilized MeHg may be high, not all MeHg is necessarily freed from the fish matrix into digestive fluids (i.e. made bioaccessible) and made available for absorption by the body following metabolism in the intestine by the gut microbiome or in the liver (bioavailable) (Afonso et al., 2015a). Thus, to postulate near total MeHg bioavailability overlooks processes that may occur before absorption and into systemic circulation. This is supported by studies reporting that $\mathrm{Hg}$ bioaccessibility is not positively correlated to concentration in the consumed food (Laird and Chan, 2013; Laird et al., 2009a). While biomarkers like blood or hair $\mathrm{Hg}$ show robust relationships to $\mathrm{Hg}$ intake (Abdelouahab et al., 2008; Cole et al., 2004; Kosatsky et al., 2000; Legrand et al., 2005; Mahaffey and Mergler, 1998), in most of these studies, $\mathrm{Hg}$ intake is estimated from food frequency questionnaires and the literature on the consumed fish species, rather than direct $\mathrm{Hg}$ measurements (Abdelouahab et al., 2008; Sunderland, 2007), meaning that exact $\mathrm{Hg}$ intake is frequently unknown. Furthermore, there is evidence that populations exhibit toxicological 
responses to $\mathrm{Hg}$ in different ways (Canuel et al., 2006a; Chapman and Chan, 2000). As $\mathrm{Hg}$ remains a contaminant of major concern (Mergler et al., 2007), it is critical we better understand its fate in the body. A cost-effective and non-invasive way of doing so is through in vitro bioaccessibility studies, to first investigate the fate of $\mathrm{Hg}$ in the gastrointestinal tract.

Many factors could be responsible for altering $\mathrm{MeHg}$ bioaccessibility from ingested food. Food matrix composition may affect the fate of $\mathrm{MeHg}$ in the body, with one study reporting that $\mathrm{Hg}$ from the flesh of a salmonid may be 6-fold more bioaccessible than that from marine mammalian organs (Laird et al., 2009a). Different levels of $\mathrm{Hg}$ bioaccessibility have also been reported for various fish species (H.-S. Wang et al., 2013). Fish handling by industries and by consumers could also alter bioaccessibility. While freezing can induce physicochemical changes to meat (Farouk et al., 2004; Sanza et al., 1999), it is widely used in fish processing to prevent spoilage (George, 1993), which could change MeHg bioaccessibility before fish become available on the market for purchase. Consumer-based food preparation can significantly transform meat, with cooking and drying reducing moisture, crude protein content and total lipids (Toyes-Vargas et al., 2016). Indeed, cooking has been found to reduce $\mathrm{Hg}$ and $\mathrm{MeHg}$ bioaccessibility (Afonso et al., 2015b; He and W.-X. Wang, 2011; Jadán Piedra et al., 2016; Ouédraogo and Amyot, 2011; Torres-Escribano et al., 2011; 2010). In vitro studies have also suggested that foods rich in plant polyphenols (such as tea) may reduce MeHg bioaccessibility (He and W.-X. Wang, 2011; Ouédraogo and Amyot, 2011; Shim et al., 2009). Dietary practices may thus alter the way MeHg is solubilized from food (bioaccessibility), and ultimately change its bioavailability. A better understanding of these processes could lead to easily implementable guidelines and recommendations to reduce $\mathrm{Hg}$ loading in fish-consuming populations.

The goal of this study was to explore how dietary practices can alter MeHg bioaccessibility, using an in vitro digestion model. We explored how various cooking techniques and the coingestion of polyphenol-rich foods could alter $\mathrm{MeHg}$ solubilization from food. We also investigated the role of specific polyphenols in driving this effect which had been hypothesized in the literature, but never confirmed. We also assessed the potential effect of combined dietary practices on $\mathrm{MeHg}$ bioaccessibility. Finally, we report how these dietary practices can affect MeHg intake and loading in the body, and propose ways to use this information to inform future research and guidelines.

\section{Methods}




\subsection{Food items, co-ingested foods and polyphenols}

Experiments were performed on swordfish, grouper, tuna and salmon filets obtained from fish markets in Montreal. These species were selected to reflect fish readily available to Canadian consumers year-round. Blueberries, coffee (Nescafé, Maxwell) and green and black teas of various brands (Twinnings, Stash, Green Sail, Salada) were purchased in Montreal supermarkets as were corn oil (Mazola) used for cooking treatments, and cornstarch (Ideal), used as a nonpolyphenol control. Pure polyphenols (gallic acid $(>97.5 \%)$, catechin $>98 \%$ ), epigallocatechin gallate $(>80 \%)$, theaflavin $(>80 \%)$, rutin $(>94 \%))$ were obtained from Sigma-Aldrich.

\subsection{Food preparation methods}

Three cooking methods were tested: grilling, frying and boiling. Grilling was performed on a Teflon-coated pan, at 100 and $150^{\circ} \mathrm{C}$ for 1 min. Frying treatments were conducted in $1 \mathrm{~mL}$ of corn oil, in glass vials heated on a burner for $1 \mathrm{~min}$. Samples were boiled in $2 \mathrm{~mL}$ of ultrapure MilliQ water (> 18.2 M $\mathrm{cm}^{-1}$ ) (EMD Millipore) in glass vials for 5 or $10 \mathrm{~min}$. Temperature was monitored throughout cooking. For freezing, fish samples were subsampled immediately following their purchase and placed in glass vials, and kept at $-20,-80^{\circ} \mathrm{C}$ or flash frozen in liquid nitrogen (then kept at $-80^{\circ} \mathrm{C}$ ). Glassware was rinsed with distilled water, soaked in a $45 \% \mathrm{HNO}, 5 \% \mathrm{HCl}$ (Fisher Scientific, ACS-pure) bath overnight and rinsed 3 times with MilliQ water before use.

For co-ingestion experiments, fish samples were digested simultaneously with either beverages or pure polyphenols. Beverages (tea, coffee, instant coffee) were prepared as per the manufacturer's instructions, and lyophilized overnight into a powder (Freezone6, Labconco). Powdered beverages were solubilized in $2 \mathrm{~mL}$ of MilliQ water, in two different doses: $40 \mathrm{mg}$ or $120 \mathrm{mg}$, and were added to fish at the start of in vitro digestion experiments. In these experiments, controls were amended with $2 \mathrm{~mL}$ of MilliQ water to adjust the volume. Pure polyphenols were solubilized in $2 \mathrm{~mL}$ of dimethyl sulfoxide (DMSO), in amounts of 5 or $10 \mathrm{mg}$, and used in in vitro digestions. Controls with no polyphenols were also amended with $2 \mathrm{~mL}$ of DMSO, to account for volume increase.

\subsection{Physiologically-based extraction test}

Many in vitro digestion protocols exist to assess bioaccessibility of nutrients and dietary compounds (Dong et al., 2016; Minekus et al., 2014; Van de Wiele et al., 2007). We selected the Physiologically-based extraction test (PBET), adapted from Ruby et al. (1996) and Ouédraogo 
and Amyot (2011), to perform digestive simulations, as it has been used frequently for metals and $\mathrm{Hg}$ (Calatayud et al., 2012; Ouédraogo and Amyot, 2011; Siedlikowski et al., 2016). All digestive simulations were performed on $1.0 \pm 0.1 \mathrm{~g}$ of fresh fish sample, in triplicate. Experimental solutions were prepared in acid-washed Teflon bottles prior to each PBET digestion. The gastric phase was prepared by combining $1.25 \mathrm{~g}$ porcine pepsin (>400 units $/ \mathrm{mg}$ ), $0.50 \mathrm{~g}$ sodium citrate (>99\%), 0.50 g malic acid (>99\%), $420 \mu \mathrm{L}$ lactic acid (>85\%) and $500 \mu \mathrm{L}$ of acetic acid $(99.7 \%)$ (purchased from Sigma-Aldrich and Fisher Scientific) in ultrapure MilliQ water in a final volume of $1 \mathrm{~L}$, and $\mathrm{pH}$ was adjusted to 2 with $\mathrm{HCl}$ (OmniTrace Ultra, EMD). The intestinal phase contained $0.60 \mathrm{~g}$ bile salts and $0.15 \mathrm{~g}$ pancreatin (4 x USP grade, lipase $>24$ units $/ \mathrm{mg}$, protease $>400 \mathrm{units} / \mathrm{mg}$ ) (SigmaAldrich), in a final volume of $250 \mathrm{~mL} 1 \mathrm{M} \mathrm{NaHCO}_{3}$.

Briefly, samples were placed in Falcon tubes with $40 \mathrm{~mL}$ of gastric solution, and were incubated at $37^{\circ} \mathrm{C}$ with agitation (100 rpm) for 1 hour. $\mathrm{pH}$ was then adjusted to 7 using $5 \mathrm{M} \mathrm{NaOH}$. Nine $\mathrm{mL}$ of intestinal solution were added to all samples, which were incubated at $37^{\circ} \mathrm{C}$ with agitation (100 rpm) for 2 hours. Following incubation, samples were centrifuged for 15 minutes at 3,000 $\mathrm{g}$. The supernatant, considered to contain the bioaccessible (solubilized) fraction of $\mathrm{MeHg}$, was isolated and used for MeHg analyses.

\subsection{Bioaccessibility}

Bioaccessibility was calculated after PBET simulations with the following equation:

[Equation 1]

$$
\% \text { bioaccessibility }=\frac{[\mathrm{MeHg}] \text { in PBET }(\mathrm{ng} / \mathrm{L}) \times \text { PBET volume }(\mathrm{L})}{[\mathrm{MeHg}] \text { in fish }(\mathrm{ng} / \mathrm{g}) \times \text { fish mass }(\mathrm{g})} \times 100
$$

with [MeHg] in PBET being $\mathrm{MeHg}$ measured in the extract of the simulated digestion, PBET volume being PBET digestive fluids volume, $[\mathrm{MeHg}]$ in fish is $[\mathrm{MeHg}]$ in initial fish sample, and fish mass is the mass of fresh fish used as input into the PBET simulation.

Multiple bioaccessibility experiments were also performed using the same commerciallypurchased fish filet over different days (stored at $4{ }^{\circ} \mathrm{C}$ between experiments). Bioaccessibility values for controls were compared across runs, and we found no statistical differences within a single fish filet (with the number of experimental days performed on each fish individual varying from 2 to 5) (Kruskal-Wallis, $P>0.05$ ) (Figure S2). This showed us that we could use multiple samples from one individual fish filet over several days with minimal impact on bioaccessibility.To compare different sets of experiments, we normalized results within each experiment to raw 
untreated fish muscle (using Equation 2), giving a percent of bioaccessible MeHg compared to controls (now normalized to $100 \%$ ).

[Equation 2]

$$
\% \text { bioaccessibility compared to control }=\frac{\text { average treated } \%}{\text { average control } \%} \times 100
$$

where average treated \% refers to the mean bioaccessibility obtained across triplicates of a given treatment, and average control \% refers to mean bioaccessibility calculated in untreated triplicates of raw fish muscle from the same run. Non-normalized control values are presented in Table 1.

\subsection{MeHg analyses}

$\mathrm{MeHg}$ in fish was measured in freeze-dried samples (Freezone6, Labconco), while MeHg following simulated digestion was analyzed in PBET fluids. Prior to analysis, both dried fish samples and PBET fluids were extracted overnight in $5 \mathrm{~mL}$ of $4 \mathrm{M} \mathrm{HNO}_{3}$ (Fisher Scientific, ACSpur) at $60^{\circ} \mathrm{C}$. MeHg in fish and PBET solutions was measured by gas chromatography and coldvapor fluorescence spectrometry (CVAFS) (Tekran 2700, Tekran Instruments Corporation), according to U.S. EPA method 1630 (detection limit of $0.01 \mathrm{ng} \mathrm{L}^{-1}$, defined as three times the standard deviation calculated on 10 ultrapure MilliQ blanks).

\subsection{Fish matrix characterization}

Lipids were quantified by gravimetry, using a method adapted from Folch et al., 1957. Nitrogen was used as a proxy for protein content and was quantified with a CHN Element Analyzer 1108 (Thermo Fisher). Moisture content in fish muscle was quantified by subtracting sample dry weight from wet weight after drying. Full methods on fish matrix characterization are presented in Supplementary Information.

\subsection{Polyphenol analyses}

Polyphenols were quantified by ultra-performance liquid chromatography with tandem mass spectrometer (UPLC-MSMS) at the Institute of Nutrition and Functional Foods (Quebec, Canada) using a Waters Acquity Ultra-Performance LC system (Waters). The full method is presented in Supplemental Information. The seven polyphenols that were quantified in coingested foods and subsequently tested in their purified form are presented in Table S2. Complete profiles of the 56 polyphenols analyzed in co-ingested foods are presented in Table S3. 


\subsection{Risk assessment}

We estimated a probable daily intake (PDI) $\left(\mathrm{ug} \mathrm{kg}^{-1}\right)$ for an average adult for each of the fish tested in this study, using the following equation:

[Equation 3]

$$
P D I=\frac{[\mathrm{MeHg} \text { in } \mathrm{fish}](\mathrm{ug} / \mathrm{g}) \times \text { average daily fish intake }(\mathrm{g})}{\text { average adult body weight }(\mathrm{kg})}
$$

where $[\mathrm{MeHg}$ in fish] is the $\mathrm{MeHg}$ concentration measured in the fish sample tested; average daily fish intake is based on fish consumption values from the Bureau of Chemical Safety of Canada (22 $\mathrm{g}$ for an adult) (Bureau of Chemical Safety Health Canada, 2004); and the average adult body weight is based on values from Nutrition Canada (60 kg for an adult) (Health Canada, 2004). PDls represent average exposure to $\mathrm{MeHg}$, if an adult consumed each fish daily over a long period of time. We then calculated a bioaccessibility-corrected PDI (PDI $\left.\left.\right|_{B A}\right)$ :

[Equation 4]

$$
P D I_{B A}=P D I x \% \text { bioaccessibility }
$$

where the \% bioaccessibility is the soluble fraction calculated from our experiments. This PDI ${ }_{B A}$ accounts for the bioaccessibility of $\mathrm{MeHg}$ in the in vitro model and the effect of food preparation and co-ingestion treatments.

\subsection{Statistical analyses}

Statistical analyses were performed with $\mathrm{R}$ software (R Development Core Team) using nonparametric methods, as normality and homoscedasticity were not respected (tested with shapiro.test() and bartlett.test() functions). Differences in bioaccessibility across treatments were compared with Kruskal-Wallis analysis of variance (kruskal() in the agricolae\{\} package) (De Mendiburu, 2012), and Bonferonni corrections were used to correct for multiple hypothesis testing. Linear regressions were used to model bioaccessibility and lipid content, and ordinations was calculated on log-transformed data. Plots were prepared using the ggplot2\{\} (Wickham, 2009) and ggbiplot \{\}$(\mathrm{Vu}, 2011)$ packages. Letters on plots denote significantly different treatments $(P<$ $0.05)$, bars present averages from triplicate PBET digestions and error bars show standard deviation of triplicates. 


\section{Results}

\subsection{Fish sample characterization and inter-fish and inter-simulation variation}

Mean MeHg concentrations in fish samples tested were below Health Canada guidelines (Food Directorate Bureau of Chemical Safety, Health Canada) (500 $\mathrm{ng} \mathrm{g}^{-1}$ for retail fish, $1000 \mathrm{ng}$ $\mathrm{g}^{-1}$ for swordfish and tuna) (average concentration in swordfish $=439 \pm 237 \mathrm{ng} \mathrm{g}^{-1}$; in grouper: $612 \pm 315 \mathrm{ng} \mathrm{g}^{-1}$; in tuna $=694 \pm 778 \mathrm{ng} \mathrm{g}^{-1}$ and in salmon $=20.1 \mathrm{ng} \mathrm{g}^{-1}$ ), except for one grouper $\left(835 \mathrm{ng} \mathrm{g}^{-1}\right)$ and one tuna (1244 $\mathrm{ng} \mathrm{g}^{-1}$ ) (Table S1). Protein, lipid and moisture content did not vary across fish species (Kruskal-Wallis, $P>0.05$ ) (Table $S 1$ ), and we found no correlation between $\mathrm{MeHg}$ bioaccessibility and lipid content in fish $(P>0.05)$ (Figure $\mathrm{S} 1$ ).

Multiple fresh filets from different individual fish were tested for each species. For grouper and tuna, we observed significant differences in $\mathrm{MeHg}$ bioaccessibility among individual fish (Kruskal-Wallis, $P<0.05$ ) (Figure S2). Differential lipid content in the muscles tested did not account for this variation, as we observed no relationship between lipids and raw bioaccessibility percentages when considering the four fish species tested in this study (Figure S2). The use of only one salmon in this study may mask potential variation between fish, and inter-individual absolute bioaccessibility may vary in ways similar to grouper and tuna. However, this study does not aim to report absolute bioaccessibility values, and trends from treatments experiments were robust across individuals for all species (see Sections 3.2 \& 3.3).

\subsection{Effects of cooking and freezing on $\mathrm{MeHg}$ bioaccessibility}

Cooking had a significant impact on MeHg bioaccessibility compared to raw controls in all fish species tested. In swordfish (Kruskal-Wallis, $P<0.05$ ) (Figure $1 \mathrm{~A}$ ), on average, $\mathrm{MeHg}$ bioaccessibility was reduced to $12.6 \pm 5.6 \%$ of control values across all cooking treatments. Grilling and frying at maximal temperatures $\left(150\right.$ and $\left.160^{\circ} \mathrm{C}\right)$ reduced bioaccessibility to $18.0 \pm$ 5.6 and $7.1 \pm 1.2 \%$ respectively, while boiling decreased bioaccessibility to $8.4 \pm 3.0 \%$ of control values (Figure 1A). Lower temperatures or cooking times did not yield significantly greater bioaccessibility losses $(P>0.05)$. The effect of cooking was consistent for grouper $(18.6 \pm 10.3 \%)$, tuna $(12.2 \pm 5.5 \%)$ and salmon $(10.9 \pm 6.7 \%)(P<0.05)$ (Figure 1B-D). In all fish species, frying tended to be the most effective at reducing MeHg bioaccessibility, but this trend was not significant $(P>0.05)$ (Figure 1). 
When swordfish samples were frozen, decreasing freezing temperatures, from -20 to -80 ${ }^{\circ} \mathrm{C}$ and flash freezing did not lead to significantly different $\mathrm{MeHg}$ bioaccessibility levels $(P>0.05)$ (Figure S3).

\subsection{Effects of co-ingested foods and polyphenols on $\mathrm{MeHg}$ bioaccessibility}

We tested the effects of co-ingested foods on $\mathrm{MeHg}$ bioaccessibility in swordfish and in tuna compared to unamended raw controls (Figure 2). As previous reports have suggested that polyphenols were responsible for altered $\mathrm{MeHg}$ bioaccessibility from fish ( $\mathrm{He}$ and W.-X. Wang, 2011; Ouédraogo and Amyot, 2011; Shim et al., 2009), we selected several polyphenol-rich foods and beverages, and one food not enriched in polyphenols (cornstarch). Our results show that green tea led to the lowest MeHg bioaccessibility values in swordfish $(22.7 \pm 3.8 \%$ when $120 \mathrm{mg}$ was used) (Figure $2 \mathrm{~A}-\mathrm{B})$ and in tuna $(34.8 \pm 5.6 \%$ with $120 \mathrm{mg}$ of tea) $(P<0.05)$ (Figure $2 \mathrm{C})$. Black tea also significantly decreased MeHg bioaccessibility in swordfish $(28.6 \pm 13.9 \%$ with 120 $\mathrm{mg}$ of tea) $(P<0.05)$. The effect of tea was greater when $120 \mathrm{mg}$ of dried tea (equivalent to approximately $375 \mathrm{~mL}$ of prepared tea) was used compared to $40 \mathrm{mg}$ (approximately $125 \mathrm{~mL}$ ). As expected, cornstarch, which contained negligible amounts of polyphenols (Table S2) had no effect on MeHg bioaccessibility (Figure 2B). Coffee and instant coffee had a slight, yet nonsignificant effect, while blueberries had no detectable impact $(P>0.05)$ (Figure 2C). Therefore, it appears only some polyphenol-rich beverages can alter $\mathrm{MeHg}$ bioaccessibility.

To identify which compounds may be responsible for this effect, we quantified 56 polyphenols in the foods that were used in bioaccessibility experiments. Of these, we found that gallic acid and flavonoids (including flavanol quercetins such as rutin, and flavon-3-ol catechins and theaflavins) were abundant in green and black tea, and in small or undetectable amounts in the other tested co-foods (Table S2). Multivariate analysis showed that treatments with the greatest decreases in bioaccessibility in this experiment were positively associated with certain polyphenol groups such as catechins, quercetins, thearubigins and kaempferols (Figure S4).

To verify the hypothetical role of these polyphenols on MeHg bioaccessibility, we repeated PBET simulations using individual purified polyphenol compounds. First, we observed that the effect of polyphenols increased with the amount added to digestion experiments, from 5 to $10 \mathrm{mg}$ (Figure 3). However, while catechin is cited in the literature as a hypothetical driver of reduced MeHg bioaccessibility (He and W.-X. Wang, 2011), we found its purified form had no significant effect $(P>0.05)$ (Figure 3A). Other forms of catechin, including cis-configuration epicatechin and epigallocatechin gallate (EGCG) did significantly limit MeHg bioaccessibility to $61.7 \pm 4.5$ and 47.0 $\pm 15.5 \%$ of unamended control, respectively $(P<0.05)$. Another flavon-3-ol (rutin) and a 
hydroxycinnamic acid (cafeic acid) also significantly reduced bioaccessibility to $55.6 \pm 1.9 \%$, and $44.8 \pm 12.5 \%$, respectively $(P<0.05)$ (Figure 3 ).

\subsection{Effects of multiple dietary practices on $\mathrm{MeHg}$ bioaccessibility}

Applied separately, cooking and polyphenols (as beverages or purified compounds) both impacted MeHg bioaccessibility compared to raw, unamended controls (Figures 1-3). We tested these treatments together within the same experiment, to assess their combined effects. Cooking swordfish (by grilling, frying or boiling) and digesting it with $120 \mathrm{mg}$ of green or black tea led to less than $1 \%$ of $\mathrm{MeHg}$ remaining bioaccessible $(P<0.05$, Figure $4 \mathrm{~A}$ and $\mathrm{B})$. Combining cooking and $10 \mathrm{mg}$ of purified gallic acid or catechin also significantly decreased MeHg bioaccessibility, to $2-17 \%$ of bioaccessible $\mathrm{MeHg}$ compared to raw unamended controls (Figure 4C and D) $(P<$ 0.05). The combined effects of cooking and co-ingested polyphenols (as beverages or purified extracts) were also observed in grouper $(P<0.05$, Figure S6) and tuna $(P<0.05$, Figure S7). In all cases, boiling combined with green or black tea were the most effective combination to reduce $\mathrm{MeHg}$ bioaccessibility, decreasing bioaccessibility by $99 \%$ compared to raw, unamended controls $(P<0.05$, Figure 4, S6 and S7).

\subsection{Bioaccessibility and risk assessments}

Finally, we compared PDIs for an average adult calculated with the MeHg concentration

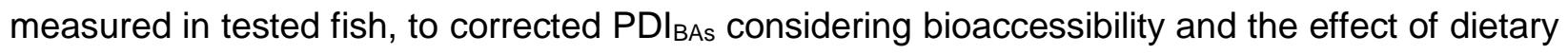
practices. This is a theoretical exercise in the absence of in vivo-validated results, and is presented here only to compare the impact of different treatments, rather than to estimate realistic PDIs. Table S4 shows that the estimated daily intake for an adult is greatly reduced when bioaccessibility is considered. All values calculated from $\mathrm{MeHg}$ concentrations were below the provisional tolerable daily intake (the maximum amount of $\mathrm{MeHg}$ that can be ingested daily over a lifetime without increasing risk of health effects) established by the World Health Organization (0.23 ug kg-1 $\left.\mathrm{d}^{-1}\right)$ (Joint FAO/WHO Expert Committee on Food Additives, 2007).

\section{Discussion}

\subsection{Cooking reduces $\mathrm{MeHg}$ bioaccessibility from fish; freezing has no effect}

Several studies have shown that cooking increases $\mathrm{Hg}$ concentrations in fish (Burger et al., 2003; Morgan et al., 1997; Perelló et al., 2008). It has been suggested that this may be due 
to weight loss due to moisture and fat loss during cooking (Morgan et al., 1997). When considering bioaccessibility however, studies consistently show a reduction of solubilized $\mathrm{Hg}$ (Ouédraogo and Amyot, 2011; Torres-Escribano et al., 2011) and MeHg (He and W.-X. Wang, 2011) from cooked fish muscle. Our results on $\mathrm{MeHg}$ bioaccessibility were consistent with these earlier findings (Figure 1). Here we expanded on these studies by comparing multiple temperatures and cooking times for each cooking treatment, and we found no significant differences between 100 and 150 ${ }^{\circ} \mathrm{C}$ for grilling, 100 and $160{ }^{\circ} \mathrm{C}$ and frying, nor for 5 and 10 minutes for boiling (Figure 1). All temperatures tested were greater than $70{ }^{\circ} \mathrm{C}$, the safe internal cooking temperature recommended by Health Canada (Health Canada First Nations Branch, Government of Canada, 2016). However, while fish cooked by consumers may reach this safe internal threshold, higher temperatures are typically used when preparing meals. Indeed, temperatures greater than 100 ${ }^{\circ} \mathrm{C}$ are typically used in studies measuring the effects of cooking on metals (Devesa et al., 2001; Ersoy et al., 2006) and heterocyclic amines (Oz et al., 2007). It is likely that the impact of heat on $\mathrm{MeHg}$ solubilization increases until a given temperature (below $100^{\circ} \mathrm{C}$ ), and further increases have no effect on $\mathrm{MeHg}$ bioaccessibility within the range of temperatures commonly used in cooking. Protein aggregation induced by high temperatures, leading to lowered pepsin digestibility, may explain these results. Cooking has also been found to induce the formation of disulfide bonds in proteins, which may further limit digestibility (Duodu et al., 2002; He et al., 2010; Kulp et al., 2003). This is supported by observations that heat induces structural changes to meat: at temperatures greater than $100^{\circ} \mathrm{C}$, oxidation can cause protein aggregation, slowing enzymatic digestion by pepsin (Bax et al., 2012).

It is important to note that these experiments were performed on small $(1 \mathrm{~g})$ sub-samples of fish muscle, which were thoroughly cooked during treatments. It is likely that in a thicker and larger fish filet more representative of an adult portion (150 g as per Health Canada) (Bureau of Chemical Safety Health Canada, 2007), cooking has more heterogeneous effects: temperature may not be even throughout the portion, and structural protein changes that might control $\mathrm{MeHg}$ bioaccessibility may vary across filet thickness. Nonetheless, these experiments on small test meals do provide insight into the effect of temperature on $\mathrm{MeHg}$ solubilization from proteins. Future experiments on cooking and $\mathrm{MeHg}$ should include portion-sized fish for a more realistic portrait of bioaccessibility.

Freezing can induce protein denaturation and physicochemical changes to meat (Farouk et al., 2004; Sanza et al., 1999). In a study of 27 samples of frozen swordfish, Torres-Escribano et al. suggested that variations in $\mathrm{Hg}$ bioaccessibility from $38-83 \%$ (64 $\pm 14 \%$ ) may be attributable to protein denaturation caused by different freezing and thawing rates, or varying storage 
temperatures (Torres-Escribano et al., 2010). In this study, we observed no relationship between bioaccessibility and colder temperatures. However, since all the fish tested in this study were purchased commercially, they had all likely been frozen before, as freezing is widely used in fish processing to prevent spoilage (George, 1993). While this industrial freezing performed after catch to conserve fish may alter bioaccessibility, our results suggest that a second freezing has no impact. Therefore, consumers who freeze commercially-purchased fish are unlikely to further impact MeHg bioaccessibility (Figure S3).

\subsection{Plant polyphenols found in tea can limit MeHg solubilization}

As plant metabolites present in all plant organs, polyphenols are an important component of human diets (Bravo, 2009), and dietary intake of flavonoids alone (which include the different catechins) has been estimated at $187 \mathrm{mg} \mathrm{d}^{-1}$ in the US (Chun et al., 2007). While they are of great interest in nutrition due to their ability to bind and precipitate certain molecules, and for their antioxidant effects in humans (Bravo, 2009), it is likely their role in metal chelation (Graham, 1992; Hider et al., 2001; Ragan et al., 1979; T. Wang et al., 2009) that drives their impact on MeHg bioaccessibility. We found that certain polyphenol-rich foods, such as green and black tea, could significantly reduce $\mathrm{MeHg}$ bioaccessibility, and that the effect increased with the amount of tea added (Figure 2). However, not all foods limited bioaccessibility: blueberries (rich in anthocyanidins) (Table S3), had no significant impact on MeHg bioaccessibility, suggesting that not all polyphenols have metal chelating properties.

The amounts of dried tea used in our experiments roughly reflect the ratio of one cup of tea consumed with one portion $(150 \mathrm{~g})$ of fish. The polyphenol molecules found in tea are suspected to reduce MeHg and Hg bioaccessibility (He and W.-X. Wang, 2011; Ouédraogo and Amyot, 2011; Shim et al., 2009) but the causal role of polyphenols was not directly investigated. Here, we tested a wide range of purified polyphenols to confirm their role in decreasing $\mathrm{MeHg}$ bioaccessibility, and to identify which compounds may be responsible for the effects of tea. Our results suggest that EGCG, caffeic acid and rutin likely have the greatest chelating properties (Figure 3), possibly forming insoluble complexes with $\mathrm{MeHg}$ and decreasing bioaccessibility. Indeed, metals chelated to polyphenols are considered to have low bioavailability: in humans, consumption of large amounts of tea or polyphenols is associated with poor iron absorption and anemia (Baynes and Bothwell, 1990). Our findings from fish and polyphenols support the results of Jadan Piedra et al., who tested the effects of catechin and tannic acids on bioaccessibility in standard MeHg aqueous solutions (Jadán Piedra et al., 2016). Other polyphenols that were measured in co-foods (Table S3) but that were not tested in their purified form could also 
contribute to the effect of tea. Indeed, kaempferols, thearubigins or quercetins other than rutin may have a similar effect as EGCG for example (Figure S4). Their role should be investigated, by testing more compounds in bioaccessibility assays. Furthermore, tea may include other compounds that could limit MeHg bioaccessibility. Tea leaves growing in certain areas of China has been found to be enriched in selenium (Molan et al., 2009), and selenium can interfere with $\mathrm{Hg}$ toxicity and bioaccessibility (Cabañero et al., 2006; 2004). While our results from purified polyphenols suggest that these compounds are the main drivers of the effects of tea on $\mathrm{MeHg}$ bioaccessibility, other molecules in the beverage may also have a role to play.

Tea polyphenols may also have other impacts on the fate of $\mathrm{MeHg}$ in the body: in vivo assays have suggested that tea could accelerate enterohepatic cycling of $\mathrm{MeHg}$ in the body (Canuel et al., 2006b) or that tea extracts may limit oxidative stress induced by $\mathrm{MeHg}$ in rats and alter its pharmacokinetics (Black et al., 2011). Green tea has also been found to increase $\mathrm{Hg}$ load in blood after consumption of MeHg-contaminated fish (Janle et al., 2015). These mechanisms should be further investigated through controlled in vivo experiments.

\subsection{Bioaccessibility studies can be used to inform current guidelines}

Studies performed on $\mathrm{Hg}$ and $\mathrm{MeHg}$ bioaccessibility in fish report values that range from $9-100 \%$, with large variations often seen within a single species (Table 1). However, over half of the values reported in Table 1 are below 50\%, suggesting that only a fraction of mercury is solubilized (bioaccessible) during simulated digestion, and thus potentially available for absorption and metabolism in the intestine and liver (bioavailable) (Afonso et al., 2015a). Current guidelines and recommendations assume that $100 \%$ of $\mathrm{MeHg}$ in fish is readily absorbed by the gastrointestinal tract (Committee on Toxicological Effects of Methylmercury, National Research Council of the United States, 2010; Ha et al., 2016). This value is based on early work on the excretion of an orally administered radio-labelled $\mathrm{MeHg}$ nitrate solution from the human body (Aberg et al., 1969). However, mercury in fish is more typically bound to sulfur-rich groups such as thiols (Clarkson and Magos, 2008; Harris, 2003), and may behave differently. This suggests that the form of $\mathrm{Hg}$ and its complexation to food or other elements may reduce its absorption, and that the $100 \% \mathrm{MeHg}$ absorption rate likely overestimates what is bioavailable from fish. When considering raw tuna, our PDI estimate which accounts for incomplete bioaccessibility ( $P D I_{B A}$ ) is 71.7\% lesser than PDI (Table S4).

These results are amplified when considering not only bioaccessibility, but also dietary practices. Indeed, when the effects of cooking are included in PDI calculations, bioaccessibility- 
corrected PDI BAs $_{\text {as }}$ are reduced by 70.6 - 98.1\% across all fish species (Table S4). As most fish consumed in North America is cooked (with the exception of sushi as well as traditional practices in indigenous communities), not including this factor in guidelines leads to overestimating $\mathrm{MeHg}$ exposure in most populations. If PDls are corrected for green and black tea consumption, the bioaccessibility-corrected PDI BA is reduced by $74.6-94.4 \%$ (Table S4). Finally, when correcting PDI for bioaccessibility data from a meal that is both cooked and consumed with a cup of tea, $\mathrm{PDI}_{\mathrm{BA}}$ drops by $99 \%$, to less than $1 \mathrm{ng} \mathrm{kg}^{-1}$ (Table S4). All PDIs presented here, calculated from commercially-purchased fish, were below the WHO's maximal provisional tolerable daily intake (PTDI) $\left(0.23 \mathrm{ug} \mathrm{kg}^{-1}\right)$ (Joint FAOMHO Expert Committee on Food Additives, 2007).

It is important to note that these $\mathrm{PDI}_{\mathrm{BAs}}$ are calculated from the results of a simplified in vitro system. While these estimates do not replace in vivo or epidemiological studies, they provide valuable insight into the ways $\mathrm{Hg}$ is solubilized from food in the gut, and may explain populationbased variations in $\mathrm{Hg}$ toxicological responses (Canuel et al., 2006a; Chapman and Chan, 2000). These bioaccessibility-based results can be used to guide more informative, but more costly in vivo studies, and in vitro assays may be of particular relevance to populations who frequently consume fish that are more heavily contaminated than commercially-monitored species. This includes recreational fishermen, coastal populations who often depend heavily on fish (CisnerosMontemayor et al., 2016), and indigenous groups like the Inuit who's reliance on marine mammals and fish exposes them to higher dietary MeHg intake (Laird et al., 2013). In communities where food insecurity is a major public health issue, such as in the Canadian Arctic, advisories can have negative outcomes (Laird et al., 2013). If validated by in vivo studies, cooking and polyphenol-rich foods could thus be easily implementable recommendations to reduce exposure to $\mathrm{Hg}$. This could promote safe consumption of fish as a source of fatty-acids, which could protect from cardiovascular disease (Mahaffey et al., 2011; Rideout and Kosatsky, 2017).

While in vitro bioaccessibility assays suggest that guidelines may overestimate $\mathrm{MeHg}$ exposure from fish, it is important to consider that these guidelines are designed to be overly conservative, in order to to protect especially vulnerable groups. These individuals, including children and pregnant women, are particularly sensitive to MeHg-induced health risks (Committee on the Toxicological Effects of MeHg). Criticism of guidelines should thus keep in mind the specific needs of vulnerable sub-groups.

\subsection{Other factors may alter $\mathrm{MeHg}$ bioaccessibility}

Other factors may also impact $\mathrm{MeHg}$ bioaccessibility, that were not taken into account here. The majority of bioaccessibility studies performed on $\mathrm{MeHg}$ in fish use commercially- 
purchased filets, hence the type of muscle and the area of the fish sampled are unknown. Fish muscles are diverse in terms of physiological function and cellular composition (Sänger and Stoiber, 2001). Furthermore, other elements found in fish could influence bioaccessibility, such as selenium and its ratio to $\mathrm{Hg}$ (Cabañero et al., 2006; 2004). Future research into withinindividual variations of $\mathrm{MeHg}$ bioaccessibility should include gradients along muscle tissues, and perform full characterizations of muscles, to further our understanding of how $\mathrm{Hg}$ binds fish muscle tissue in fish.

$\mathrm{MeHg}$ bioaccessibility has also been found to be limited by co-ingested plant products such as dietary fibers (Shim et al., 2009) and plant cell walls compounds (lignin, methylcellulose, pectin) (Jadán Piedra et al., 2016). Studies conducted on rats fed with intrinsically MeHgcontaminated food matrices also show that plant compounds can limit absorption (Yannai and Sachs, 1993). Current guidelines do not take into consideration complex diets, accounting only for $\mathrm{MeHg}$ measured in fish muscle. Our results combined with others from the literature suggest that ignoring plant-based co-foods, which contain polyphenols and dietary fiber may lead to overestimations of $\mathrm{Hg}$ intake from fish. Risk assessments also overlook cooking and the combined effect of different processes involved in preparing a meal, contributing to this lack of realism.

Host genetics, including the gut microbiome could also potentially alter the fate of $\mathrm{Hg}$ in the body, as has been observed with other metals. For example, toxic species of arsenic and bismuth can be produced by gut bacteria prior to absorption by the epithelial lining (Diaz-Bone and Van de Wiele, 2010; Van de Wiele et al., 2010), and Laird et al. observed increased arsenic bioaccessibility in the presence of a simulated gut microbiome community, compared to sterile conditions (Laird et al., 2009b). While in vivo methylation would increase Hg toxicity, this pathway has not yet be observed in primates (Gilmour et al., 2013; Martín-Doimeadios et al., 2017). Evidence for $\mathrm{MeHg}$ demethylation by the microbiome has been reported from mice models, producing poorly-absorbed inorganic $\mathrm{Hg}$ (Rowland, 1988). Meanwhile the mer operon, responsible for mercury resistance and cell membrane transport, is frequent: a study of 800 antibiotic-resistance plasmids from Gram- bacteria have been found to carry the operon (Schottel et al., 1974). This may allow it to alter Hg cycling in the gut. Lactic acid bacteria have been found to reduce $\mathrm{Hg}$ bioaccessibility in mushrooms and aqueous solutions, but not in seafood (JadánPiedra et al., 2017a; 2017b). Interactions between dietary $\mathrm{Hg}$ and the microbiome are thus unclear, and should be explored further.

4.5. In vitro findings must be validated to improve current risk assessments 
In vitro gastrointestinal models are useful to understand the fate of food components and contaminants in the human body, as they are inexpensive and easy to use. They allow for screening high numbers of samples in a controlled setting, can be validated with reference materials, and avoid ethical considerations of using model animals, which can be more or less relevant to humans (Fernández-García et al., 2009).

Bioaccessibility assays have been suggested as a way to improve risk assessments (Cardoso et al., 2014) and guidelines (Ángeles García et al., 2016). However, in vitro models are rarely validated because of the lack of in vivo experiments using consumer products in contaminant studies (Brandon et al., 2006; Hur et al., 2011). In vitro studies could be improved by integrating cell cultures such as Caco-2, to account for membrane transport (Hur et al., 2011; Moreda-Piñeiro et al., 2011), but this does not take into account whole-body processes that could alter the fate of $\mathrm{Hg}$, such as stimulation of the enterohepatic cycle (Canuel et al., 2006b) or interactions with the gut microbiome, which are also determinants of bioavailability. Future work should involve in vivo experiments, to validate the effects of dietary practices and co-foods on $\mathrm{Hg}$ bioaccessibility. In vitro investigations remain useful, as they offer insight into the structural and complexation changes that $\mathrm{Hg}$ undergoes during food preparation and digestion, and provide evidence that it would be worthwhile to embark on costly and ethically-loaded in vivo assays. We recommend that further work on the fate of $\mathrm{MeHg}$ in the body should be performed in animal models such as swine, which are considered appropriate for human health risk assessments (Moreda-Piñeiro et al., 2011).

Culturally-specific guidelines may also be necessary: for example, current pharmacokinetic models are poor predictors of $\mathrm{Hg}$ burden in Canadian indigenous populations (Canuel et al., 2006a), who have a different genetic background, but who also have specific dietary practices regarding food preparation and co-foods. This supports observations made by a European study on MeHg risk assessment, which showed that guidelines should be population and country-specific (Jacobs et al., 2016). While smaller, low-trophic level fish could be recommended over more contaminated species to promote fish intake, this solution may not be implementable in developing countries or coastal populations who rely on high-trophic level organisms. Risk assessments based from validated bioaccessibility data could provide specific recommendations for various populations, who are exposed to dietary $\mathrm{MeHg}$ in different ways. This may lead to easily applicable, non-invasive guidelines that allow a population to adapt its food preparation to limit exposure to $\mathrm{Hg}$ in culturally important foods. This could be of critical importance for coastal indigenous populations, which have a per capita fish consumption 15 times greater than non-indigenous peoples (Cisneros-Montemayor et al., 2016). Altering MeHg 
554 bioaccessibility through dietary practices in these populations could have important 555 consequences on $\mathrm{Hg}$ absorption and health. Since fish are an excellent source of protein, 556 vitamins, fatty acids and minerals which feed a significant portion of the world's population and

557 are associated with cardiac health, it is critical to better understand the risk that $\mathrm{Hg}$ in fish 558 represents to human health. 


\section{References}

Abdelouahab, N., Vanier, C., Baldwin, M., Garceau, S., Lucotte, M., Mergler, D., 2008. Ecosystem matters: Fish consumption, mercury intake and exposure among fluvial lake fish-eaters. Science of the Total Environment 407, 154-164. doi:10.1016/j.scitotenv.2008.09.004

Aberg, B., Ekman, L., Falk, R., Greitz, U., Persson, G., Snihs, J.O., 1969. Metabolism of methyl mercury $\left({ }^{203} \mathrm{Hg}\right)$ compounds in man. Archives of Environmental Health: An International Journal 19, 478-484. doi:10.1080/00039896.1969.10666872

Afonso, C., Costa, S., Cardoso, C., Bandarra, N.M., Batista, I., Coelho, I., Castanheira, I., Nunes, M.L., 2015a. Evaluation of the risk/benefit associated to the consumption of raw and cooked farmed meagre based on the bioaccessibility of selenium, eicosapentaenoic acid and docosahexaenoic acid, total mercury, and methylmercury determined by an in vitro digestion model. Food Chemistry 170, 249-256. doi:10.1016/j.foodchem.2014.08.044

Afonso, C., Costa, S., Cardoso, C., Oliveira, R., Lourenço, H.M., Viula, A., Batista, I., Coelho, I., Nunes, M.L., 2015b. Benefits and risks associated with consumption of raw, cooked, and canned tuna (Thunnus spp.) based on the bioaccessibility of selenium and methylmercury. Environmental Research 1-8. doi:10.1016/j.envres.2015.04.019

Ángeles García, M., Núñez, R., Alonso, J., Melgar, M.J., 2016. Total mercury in fresh and processed tuna marketed in Galicia (NW Spain) in relation to dietary exposure. Environ Sci Pollut Res 1-10. doi:10.1007/s11356-016-7634-9

Bax, M.-L., Aubry, L., Ferreira, C., Daudin, J.-D., Gatellier, P., Rémond, D., Santé-Lhoutellier, V., 2012. Cooking temperature is a key determinant of in vitro meat protein digestion rate: investigation of underlying mechanisms. J. Agric. Food Chem. 60, 2569-2576. doi:10.1021/jf205280y

Baynes, R.D., Bothwell, T.H., 1990. Iron Deficiency. Annu. Rev. Nutr. 10, 133-148. doi:10.1146/annurev.nu.10.070190.001025

Black, P., Niu, L., Sachdeva, M., Lean, D., Poon, R., Bowers, W.J., Chan, H.M., Arnason, J.T., Pelletier, G., 2011. Modulation of the effects of methylmercury on rat neurodevelopment by co-exposure with Labrador Tea (Rhododendron tomentosum ssp. subarcticum). Food and Chemical Toxicology 49, 2336-2342. doi:10.1016/j.fct.2011.06.035

Brandon, E.F.A., Oomen, A.G., Rompelberg, C.J.M., Versantvoort, C.H.M., van Engelen, J.G.M., Sips, A.J.A.M., 2006. Consumer product in vitro digestion model: Bioaccessibility of contaminants and its application in risk assessment. Regulatory Toxicology and Pharmacology 44, 161-171. doi:10.1016/j.yrtph.2005.10.002

Bravo, L., 2009. Polyphenols: Chemistry, dietary sources, metabolism, and nutritional significance. Nutrition Reviews 56, 317-333. doi:10.1111/j.1753-4887.1998.tb01670.x

Bureau of Chemical Safety Health Canada, 2007. Human health risk assessment of mercury in fish and health benefits of fish consumption.

Bureau of Chemical Safety Health Canada, 2004. Fish consumption: Review and recommendation of current intake figures for Canadian consumers.

Burger, J., Dixon, C., Boring, S., Gochfeld, M., 2003. Effect of deep-frying fish on risk from mercury. Journal of Toxicology and Environmental Health, Part A 66, 817-828. doi:10.1080/15287390306382

Cabañero, A.I., Madrid, Y., Cámara, C., 2006. Selenium long-term administration and its effect on mercury toxicity. J. Agric. Food Chem. 54, 4461-4468. doi:10.1021/jf0603230

Cabañero, A.I., Madrid, Y., Cámara, C., 2004. Selenium and mercury bioaccessibility in fish samples: an in vitro digestion method. Analytica Chimica Acta 526, 51-61. doi:10.1016/j.aca.2004.09.039

Calatayud, M., Devesa, V., Virseda, J.R., Barberá, R., Montoro, R., Vélez, D., 2012. Mercury and selenium in fish and shellfish: Occurrence, bioaccessibility and uptake by Caco-2 cells. 
Food and Chemical Toxicology 50, 2696-2702. doi:10.1016/j.fct.2012.05.028

Canuel, R., de Grosbois, S.B., Atikessé, L., Lucotte, M., Arp, P., Ritchie, C., Mergler, D., Chan, H.M., Amyot, M., Anderson, R., 2006a. New Evidence on Variations of Human Body Burden of Methylmercury from Fish Consumption. Environ. Health Perspect. 114, 302-306. doi:10.1289/ehp.7857

Canuel, R., de Grosbois, S.B., Lucotte, M., Atikessé, L., Larose, C., Rheault, I., 2006b. New evidence on the effects of tea on mercury metabolism in humans. Archives of Environmental \& Occupational Health 61, 232-238. doi:10.3200/AEOH.61.5.232-238

Cardoso, C., Afonso, C., Lourenço, H., Costa, S., Nunes, M.L., 2014. Bioaccessibility assessment methodologies and their consequences for the risk-benefit evaluation of food. Trends in Food Science \& Technology 1-19. doi:10.1016/j.tifs.2014.08.008

Chapman, L., Chan, H.M., 2000. The influence of nutrition on methyl mercury intoxication. Environ. Health Perspect. 108, 29-56.

Chun, O.K., Chung, S.J., Song, W.O., 2007. Estimated dietary flavonoid intake and major food sources of U.S. adults. The Journal of Nutrition 137, 1244-1252.

Cisneros-Montemayor, A.M., Pauly, D., Weatherdon, L.V., Ota, Y., 2016. A global estimate of seafood consumption by coastal Indigenous peoples. PLoS ONE 11, e0166681-16. doi:10.1371/journal.pone.0166681

Clarkson, T.W., Magos, L., 2008. The toxicology of mercury and its chemical compounds. Critical Reviews in Toxicology 36, 609-662. doi:10.1080/10408440600845619

Cole, D.C., Kearney, J., Sanin, L.H., LeBlanc, A., Weber, J.-P., 2004. Blood mercury levels among Ontario anglers and sport-fish eaters. Environmental Research 95, 305-314. doi:10.1016/j.envres.2003.08.012

Committee on Toxicological Effects of Methylmercury, National Research Council of the United States, 2010. Toxicological effects of methylmercury. National Academies of Science., Washington.

De Mendiburu, F., 2012. R package agricolae: Statistical Procedures for Agricultural Research.

Devesa, V., Martínez, A., Súñer, M.A., Vélez, D., Almela, C., Montoro, R., 2001. Effect of cooking temperatures on chemical changes in species of organic arsenic in seafood. J. Agric. Food Chem. 49, 2272-2276. doi:10.1021/jf0013297

Diaz-Bone, R.A., Van de Wiele, T., 2010. Biotransformation of metal(loid)s by intestinal microorganisms. Pure and Applied Chemistry 82, 1-19. doi:10.1351/PAC-CON-09-06-08

Dong, Z., Yan, K., Liu, Y., Naidu, R., Duan, L., Wijayawardena, A., Semple, K.T., Rahman, M.M., 2016. A meta-analysis to correlate lead bioavailability and bioaccessibility and predict lead bioavailability. Environment International 92-93, 139-145. doi:10.1016/j.envint.2016.04.009

Duodu, K.G., Nunes, A., Delgadillo, I., Parker, M.L., Mills, E.N.C., Belton, P.S., Taylor, J.R.N., 2002. Effect of grain structure and cooking on sorghum and maize in vitro protein digestibility. Journal of Cereal Science 35, 161-174. doi:10.1006/jcrs.2001.0411

Ersoy, B., Yanar, Y., Küçükgülmez, A., Çelik, M., 2006. Effects of four cooking methods on the heavy metal concentrations of sea bass fillets (Dicentrarchus labrax Linne, 1785). Food Chemistry 99, 748-751. doi:10.1016/j.foodchem.2005.08.055

Farouk, M.M., Wieliczko, K.J., Merts, I., 2004. Ultra-fast freezing and low storage temperatures are not necessary to maintain the functional properties of manufacturing beef. Meat Science 66, 171-179. doi:10.1016/S0309-1740(03)00081-0

Fernández-García, E., Carvajal-Lérida, I., Pérez-Gálvez, A., 2009. In vitro bioaccessibility assessment as a prediction tool of nutritional efficiency. Nutrition Research 29, 751-760. doi:10.1016/j.nutres.2009.09.016

Folch, J., Lees, M., Sloane Stanley, G.H., 1957. A simple method for the isolation and purification of total lipides from animal tissues. Journal of Biological Chemistry 226, 497509. 
Food and Agriculture Organization, 2016. The State of World Fisheries and Aquaculture (SOFIA). Department of Food and Agriculture Organization of the United Nations.

Food Directorate Bureau of Chemical Safety, Health Canada, n.d. Canadian standards (maximum levels) for various chemical contaminants in foods.

George, R.M., 1993. Freezing proceseses used in the food industry. Trends in Food Science \& Technology 4, 134-138. doi:10.1016/0924-2244(93)90032-6

Gilmour, C.C., Podar, M., Bullock, A.L., Graham, A.M., Brown, S.D., Somenahally, A.C., Johs, A., Hurt, R.A., Jr., Bailey, K.L., Elias, D.A., 2013. Mercury methylation by novel microorganisms from new environments. Environ. Sci. Technol. 47, 11810-11820. doi:10.1021/es403075t

Graham, H.N., 1992. Green tea composition, consumption, and polyphenol chemistry. Preventive Medicine 21, 334-350. doi:10.1016/0091-7435(92)90041-F

Ha, E., Basu, N., Bose-O’Reilly, S., Dórea, J.G., McSorley, E., Sakamoto, M., Chan, H.M., 2016. Current progress on understanding the impact of mercury on human health. Environmental Research 152, 419-433. doi:10.1016/j.envres.2016.06.042

Harris, H.H., 2003. The chemical form of mercury in fish. Science 301, 1203-1203. doi:10.1126/science. 1085941

He, M., Ke, C.-H., Wang, W.-X., 2010. Effects of cooking and subcellular distribution on the bioaccessibility of trace elements in two marine fish species. J. Agric. Food Chem. 58, 3517-3523. doi:10.1021/jf100227n

He, M., Wang, W.-X., 2011. Factors affecting the bioaccessibility of methylmercury in several marine fish species. J. Agric. Food Chem. 59, 7155-7162. doi:10.1021/jf201424g

Health Canada, 2004. Canadian Community Health Survey, cycle 2.2.

Health Canada First Nations Branch, Government of Canada, 2016. Fish and Shellfish Safety Food Safety: Information for First Nations.

Hider, R.C., Liu, Z.D., Khodr, H.H., 2001. Metal chelation of polyphenols, in: Flavonoids and Other Polyphenols, Methods in Enzymology. Elsevier, pp. 190-203. doi:10.1016/S00766879(01)35243-6

Hur, S.J., Lim, B.O., Decker, E.A., McClements, D.J., 2011. In vitro human digestion models for food applications. Food Chemistry 125, 1-12. doi:10.1016/j.foodchem.2010.08.036

Jacobs, S., Sioen, I., Jacxsens, L., Domingo, J.L., Sloth, J.J., Marques, A., Verbeke, W., 2016. Risk assessment of methylmercury in five European countries considering the national seafood consumption patterns. Food and Chemical Toxicology 1-9. doi:10.1016/j.fct.2016.10.026

Jadán Piedra, C., Sánchez, V., Vélez, D., Devesa, V., 2016. Reduction of mercury bioaccessibility using dietary strategies. LWT - Food Science and Technology 71, 10-16. doi:10.1016/j.lwt.2016.03.015

Jadán-Piedra, C., Alcantara, C., Monedero, V., Zuniga, M., Vélez, D., Devesa, V., 2017a. The use of lactic acid bacteria to reduce mercury bioaccessibility. Food Chemistry 228, 158166. doi:10.1016/j.foodchem.2017.01.157

Jadán-Piedra, C., Baquedano, M., Puig, S., Vélez, D., Devesa, V., 2017b. Use of Saccharomyces cerevisiae to reduce the bioaccessibility of mercury from food. J. Agric. Food Chem. acs.jafc.7b00285-33. doi:10.1021/acs.jafc.7b00285

Janle, E.M., Freiser, H., Manganais, C., Chen, T.-Y., Craig, B.A., Santerre, C.R., 2015. Green tea increases the concentration of total mercury in the blood of rats following an oral fish tissue bolus. BioMed research international 2015, 1-6. doi:10.1155/2015/320936

Joint FAO/WHO Expert Committee on Food Additives, 2007. Evaluation of certain food additives and contaminants, WHO technical report series no. Rome, Italy.

Kosatsky, T., Przybysz, R., Armstrong, B., 2000. Mercury exposure in Montrealers who eat St. Lawrence River sportfish. Environmental Research 84, 36-43. doi:10.1006/enrs.2000.4073

Kulp, K.S., Fortson, S.L., Knize, M.G., Felton, J.S., 2003. An in vitro model system to predict the 
bioaccessibility of heterocyclic amines from a cooked meat matrix. Food and Chemical Toxicology 41, 1701-1710. doi:10.1016/S0278-6915(03)00197-2

Laird, B.D., Chan, H.M., 2013. Bioaccessibility of metals in fish, shellfish, wild game, and seaweed harvested in British Columbia, Canada. Food and Chemical Toxicology 1-31. doi:10.1016/j.fct.2013.04.033

Laird, B.D., Goncharov, A.B., Egeland, G.M., Man Chan, H., 2013. Dietary advice on Inuit traditional food use needs to balance benefits and risks of mercury, selenium, and n3 fatty acids. Journal of Nutrition 143, 923-930. doi:10.3945/jn.112.173351

Laird, B.D., Shade, C., Gantner, N., Chan, H.M., Siciliano, S.D., 2009a. Bioaccessibility of mercury from traditional northern country foods measured using an in vitro gastrointestinal model is independent of mercury concentration. Science of the Total Environment 407, 6003-6008. doi:10.1016/j.scitotenv.2009.08.014

Laird, B.D., Yeung, J., Peak, D., Siciliano, S.D., 2009b. Nutritional status and gastrointestinal microbes affect arsenic bioaccessibility from soils and mine tailings in the Simulator of the Human Intestinal Microbial Ecosystem. Environ. Sci. Technol. 43, 8652-8657. doi:10.1021/es900837y

Legrand, M., Arp, P., Ritchie, C., Chan, H.M., 2005. Mercury exposure in two coastal communities of the Bay of Fundy, Canada. Environmental Research 98, 14-21. doi:10.1016/j.envres.2004.07.006

Legrand, M., Feeley, M., Tikhonov, C., Schoen, D., Li-Muller, A., 2010. Methylmercury blood guidance values for Canada. Canadian Journal of Public Health 101, 28-31.

Mahaffey, K.R., Mergler, D., 1998. Blood levels of total and organic mercury in residents of the upper St. Lawrence River basin, Québec: Association with age, gender, and fish consumption. Environmental Research 77, 104-114. doi:10.1006/enrs.1998.3834

Mahaffey, K.R., Sunderland, E.M., Chan, H.M., Choi, A.L., Grandjean, P., Mariën, K., Oken, E., Sakamoto, M., Schoeny, R., Weihe, P., Yan, C.-H., Yasutake, A., 2011. Balancing the benefits of $n-3$ polyunsaturated fatty acids and the risks of methylmercury exposure from fish consumption. Nutrition Reviews 69, 493-508. doi:10.1111/j.1753-4887.2011.00415.x

Martín-Doimeadios, R.C.R., Mateo, R., Jiménez-Moreno, M., 2017. Is gastrointestinal microbiota relevant for endogenous mercury methylation in terrestrial animals? Environmental Research 152, 454-461. doi:10.1016/j.envres.2016.06.018

Mergler, D., Anderson, H.A., Chan, L.H.M., Mahaffey, K.R., Murray, M., Sakamoto, M., Stern, A.H., 2007. Methylmercury exposure and health effects in humans: A worldwide concern. A Journal of the Human Environment 36, 3-11. doi:10.1579/0044-

7447(2007)36\%5B3:MEAHEI\%5D2.0.CO;2

Miettinen, J., Rahola, T., Hattula, T., Rissanen, K., Tillander, M., 1971. Elimination of 203Hgmethylmercury in man. Ann. Clin. Res. 3, 116-122.

Minekus, M., Alminger, M., Alvito, P., Ballance, S., Bohn, T., Bourlieu, C., Carrière, F., Boutrou, R., Corredig, M., Dupont, D., Dufour, C., Egger, L., Golding, M., Karakaya, S., Kirkhus, B., Le Feunteun, S., Lesmes, U., Macierzanka, A., Mackie, A., Marze, S., McClements, D.J., Ménard, O., Recio, I., Santos, C.N., Singh, R.P., Vegarud, G.E., Wickham, M.S.J., Weitschies, W., Brodkorb, A., 2014. A standardised static in vitro digestion method suitable for food - an international consensus. Food Funct. 5, 1113-1124. doi:10.1039/C3FO60702J

Molan, A.L., Flanagan, J., Wei, W., Moughan, P.J., 2009. Selenium-containing green tea has higher antioxidant and prebiotic activities than regular green tea. Food Chemistry 114, 829835. doi:10.1016/j.foodchem.2008.10.028

Moreda-Piñeiro, J., Moreda-Piñeiro, A., Romarís-Hortas, V., Moscoso-Pérez, C., López-Mahía, P., Muniategui-Lorenzo, S., Bermejo-Barrera, P., Prada-Rodríguez, D., 2011. In-vivo and invitro testing to assess the bioaccessibility and the bioavailability of arsenic, selenium and mercury species in food samples. TrAC Trends in Analytical Chemistry 30, 324-345.

doi:10.1016/j.trac.2010.09.008 
Morgan, J.N., Berry, M.R., Graves, R.L., 1997. Effects of commonly used cooking practices on total mercury concentration in fish and their impact on exposure assessments. Journal of Exposure Analysis and Environmental Epidemiology 7, 119-133.

Ouédraogo, O., Amyot, M., 2011. Effects of various cooking methods and food components on bioaccessibility of mercury from fish. Environmental Research 111, 1064-1069. doi:10.1016/j.envres.2011.09.018

Oz, F., Kaban, G., Kaya, M., 2007. Effects of cooking methods on the formation of heterocyclic aromatic amines of two different species trout. Food Chemistry 104, 67-72. doi:10.1016/j.foodchem.2006.10.075

Perelló, G., Martí-Cid, R., Llobet, J.M., Domingo, J.L., 2008. Effects of Various Cooking Processes on the Concentrations of Arsenic, Cadmium, Mercury, and Lead in Foods. J. Agric. Food Chem. 56, 11262-11269. doi:10.1021/jf802411q

$\mathrm{R}$ Development Core Team, R: a language and environment for statistical computing. $\mathrm{R}$ Foundation for Statistical Computing.

Ragan, M.A., Smidsrød, O., Larsen, B., 1979. Chelation of divalent metal ions by brown algal polyphenols. Marine Chemistry 7, 265-271. doi:10.1016/0304-4203(79)90043-4

Rideout, K., Kosatsky, T., 2017. Fish for dinner? Balancing risks, benefits, and values in formulating food consumption advice. Risk Analysis 16, 1885-12. doi:10.1111/risa.12769

Rowland, I.R., 1988. Interactions of the gut microflora and the host in toxicology. Toxicologic Pathology 16, 147-153. doi:10.1177/019262338801600207

Sanza, P.D., de Elvira, C., Martino, M., Zaritzky, N., Otero, L., Carrasco, J.A., 1999. Freezing rate simulation as an aid to reducing crystallization damage in foods. Meat Science 52, 275-278. doi:10.1016/S0309-1740(99)00002-9

Sänger, A.M., Stoiber, W., 2001. 7. Muscle fiber diversity and plasticity, in: Fish Physiology. pp. 187-250.

Schottel, J., Mandal, A., Clark, D., Silver, S., Hedges, R.W., 1974. Volatilisation of mercury and organomercurials determined by inducible R-factor systems in enteric bacteria. Nature 251, 335-337. doi:10.1038/251335a0

Shim, S.-M., Ferruzzi, M.G., Kim, Y.-C., Janle, E.M., Santerre, C.R., 2009. Impact of phytochemical-rich foods on bioaccessibility of mercury from fish. Food Chemistry 112, 4650. doi:10.1016/j.foodchem.2008.05.030

Siedlikowski, M., Bradley, M., Kubow, S., Goodrich, J.M., Franzblau, A., Basu, N., 2016. Bioaccessibility and bioavailability of methylmercury from seafood commonly consumed in North America - In vitro and epidemiological studies. Environmental Research 149, $266-$ 273. doi:10.1016/j.envres.2016.02.013

Sunderland, E.M., 2007. Mercury exposure from domestic and imported estuarine and marine fish in the U.S. seafood market. Environ. Health Perspect. 115, 235-242. doi:10.1289/ehp.9377

Torres-Escribano, S., Ruiz, A., Barrios, L., Vélez, D., Montoro, R., 2011. Influence of mercury bioaccessibility on exposure assessment associated with consumption of cooked predatory fish in Spain. J. Sci. Food Agric. 91, 981-986. doi:10.1002/jsfa.4241

Torres-Escribano, S., Vélez, D., Montoro, R., 2010. Mercury and methylmercury bioaccessibility in swordfish. Food Additives and Contaminants 27, 327-337. doi:10.1080/19440040903365272

Toyes-Vargas, E., Robles-Romo, A., Méndez, L., Palacios, E., Civera, R., 2016. Changes in fatty acids, sterols, pigments, lipid classes, and heavy metals of cooked or dried meals, compared to fresh marine by-products. Animal Feed Science and Technology 221, 195205. doi:10.1016/j.anifeedsci.2016.09.004

Van de Wiele, T., Gallow, C.M., Kubachka, K.M., Creed, J.T., Basta, N., Dayton, E.A., Whitacre, S., Laing, Du, G., Bradham, K., 2010. Arsenic metabolism by human gut microbiota upon in vitro digestion of contaminated soils 1-7. doi:10.1289/ehp.0901794[Online26March 
Van de Wiele, T.R., Oomen, A.G., Wragg, J., Cave, M., Minekus, M., Hack, A., Cornelis, C., Rompelberg, C.J.M., De Zwart, L.L., Klinck, B., Van Wijnen, J., Verstraete, W., Sips, A.J.A.M., 2007. Comparison of five in vitro digestion models to in vivo experimental results: Lead bioaccessibility in the human gastrointestinal tract. Journal of Environmental Science and Health, Part A 42, 1203-1211. doi:10.1080/10934520701434919

Vu, V.Q., 2011. vqv/ggbiplot.

Wang, H.-S., Xu, W.-F., Chen, Z.-J., Cheng, Z., Ge, L.-C., Man, Y.-B., Giesy, J.P., Du, J., Wong, C.K.C., Wong, M.H., 2013. In vitro estimation of exposure of Hong Kong residents to mercury and methylmercury via consumption of market fishes. Journal of Hazardous Materials 248-249, 387-393. doi:10.1016/j.jhazmat.2012.12.060

Wang, T., Jónsdóttir, R., Ólafsdóttir, G., 2009. Total phenolic compounds, radical scavenging and metal chelation of extracts from Icelandic seaweeds. Food Chemistry 116, 240-248. doi:10.1016/j.foodchem.2009.02.041

Wickham, H., 2009. ggplot2: elegant graphics for data analysis. Springer Science \& Business Media, New York.

Yannai, S., Sachs, K.M., 1993. Absorption and accumulation of cadmium, lead and mercury from foods by rats. Food and Chemical Toxicology 31, 351-355. doi:10.1016/02786915(93)90190-A 
${ }_{834}$ Table legends

835

836

Table 1. Total $\mathrm{Hg}$ and $\mathrm{MeHg}$ bioaccessibility (\%) measured in fresh, raw fish muscle in this study and from the literature. Values presented are averages and standard deviations (SD) 


\section{Figure legends}

Figure 1. Effect of cooking on MeHg bioaccessibility in A. swordfish, B. grouper, C. tuna and D. salmon. Results were normalized to controls at $100 \%$, to allow comparison across experiments (see Methods). Letters denote significantly different treatments (Kruskal-Wallis, $P<0.05$ ) after Bonferonni multiple comparison correction, bars present averages from triplicate PBET digestions and error bars show standard deviation of triplicates.

Figure 2. Effect of polyphenol-rich beverages and foods on $\mathrm{MeHg}$ bioaccessibility in A. \& B. swordfish and C. tuna. Results were normalized to controls at $100 \%$, to allow comparison across experiments (see Methods). Letters denote significantly different treatments (Kruskal-Wallis, $P<$ 0.05) after Bonferonni multiple comparison correction, bars present averages from triplicate PBET digestions and error bars show standard deviation of triplicates.

Figure 3. Effect of pure polyphenols on MeHg bioaccessibility in swordfish. A \& B. Gallic acid, epigallocatechin gallate, rutin and caffeic acid lead to significant decreases in $\mathrm{MeHg}$ bioaccessibility (Kruskal-Wallis, $P<0.05$ ). Results were normalized to controls at $100 \%$, to allow comparison across experiments (see Methods). Letters denote significantly different treatments (Kruskal-Wallis, $P<0.05$ ) after Bonferonni multiple comparison correction, bars present averages from triplicate PBET digestions and error bars show standard deviation of triplicates.

Figure 4. Mixed effect of cooking and polyphenols/polyphenol-rich beverages on $\mathrm{MeHg}$ bioaccessibility in swordfish for polyphenol-rich beverages and foods (A. black tea, B. green tea) and for pure polyphenols (C. gallic acid, D. catechin). Results were normalized to controls at $100 \%$, to allow comparison across experiments (see Methods). Letters denote significantly different treatments (Kruskal-Wallis, $P<0.05$ ) after Bonferonni multiple comparison correction, bars present averages from triplicate PBET digestions and error bars show standard deviation of triplicates. 

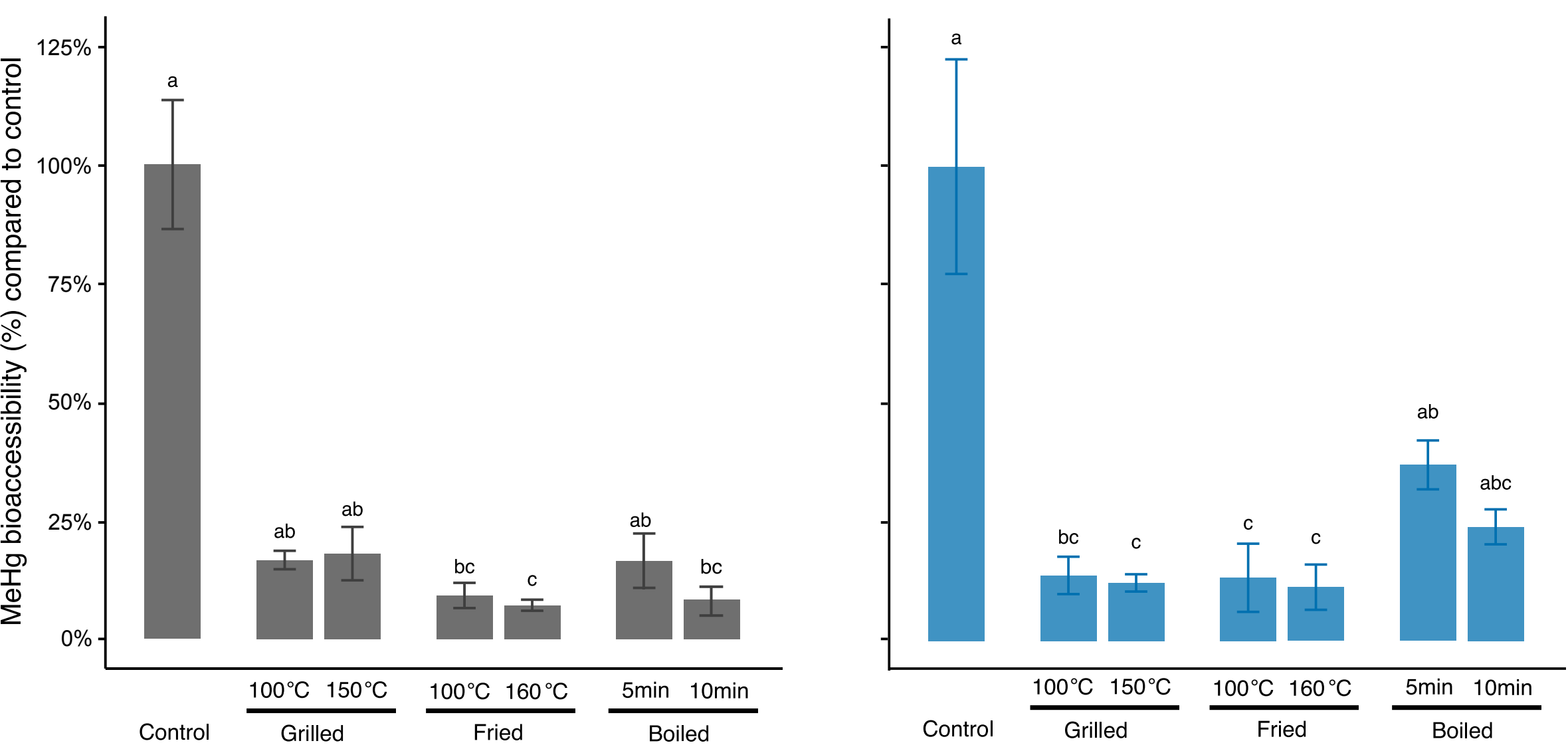

c.

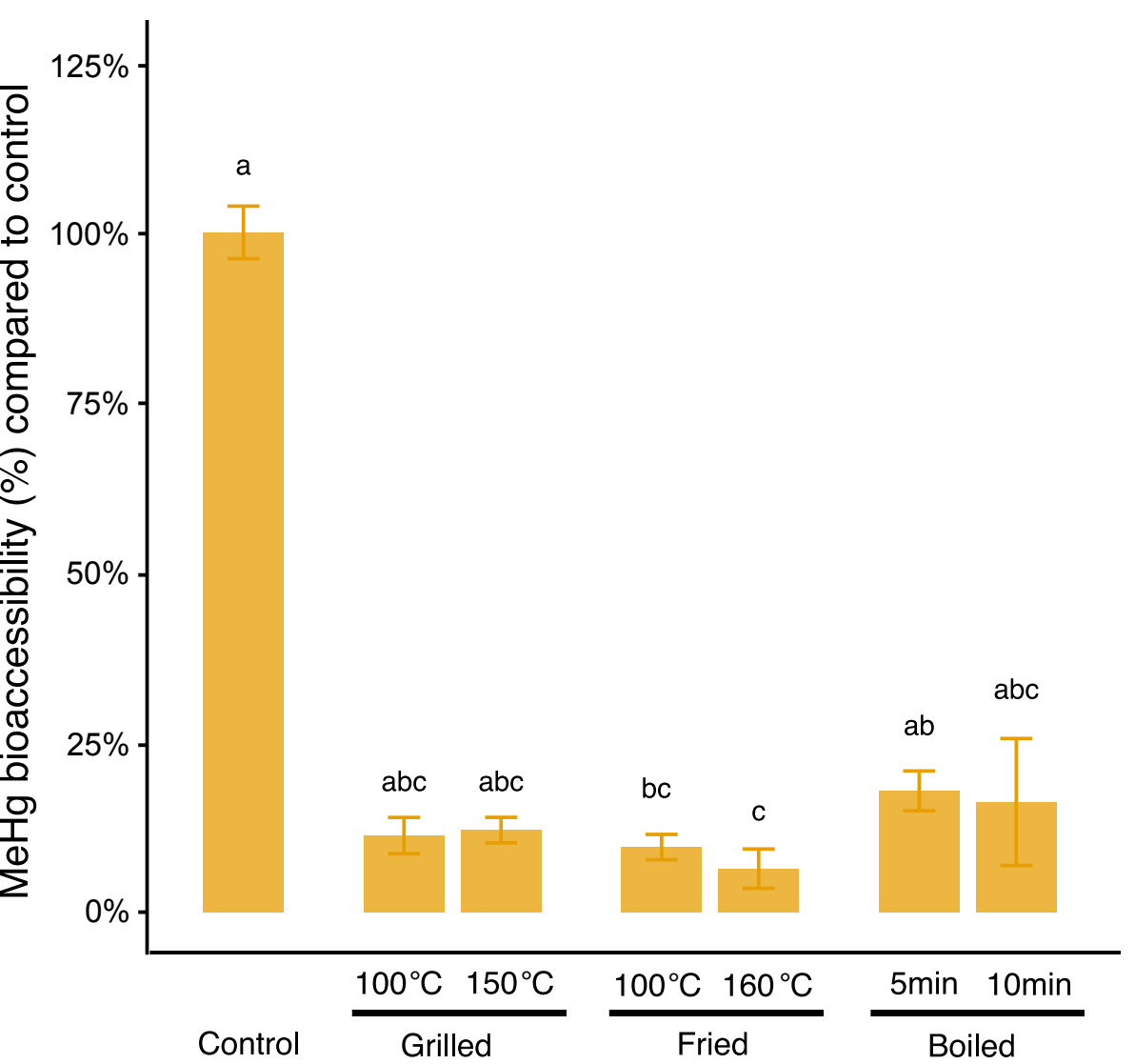

D.

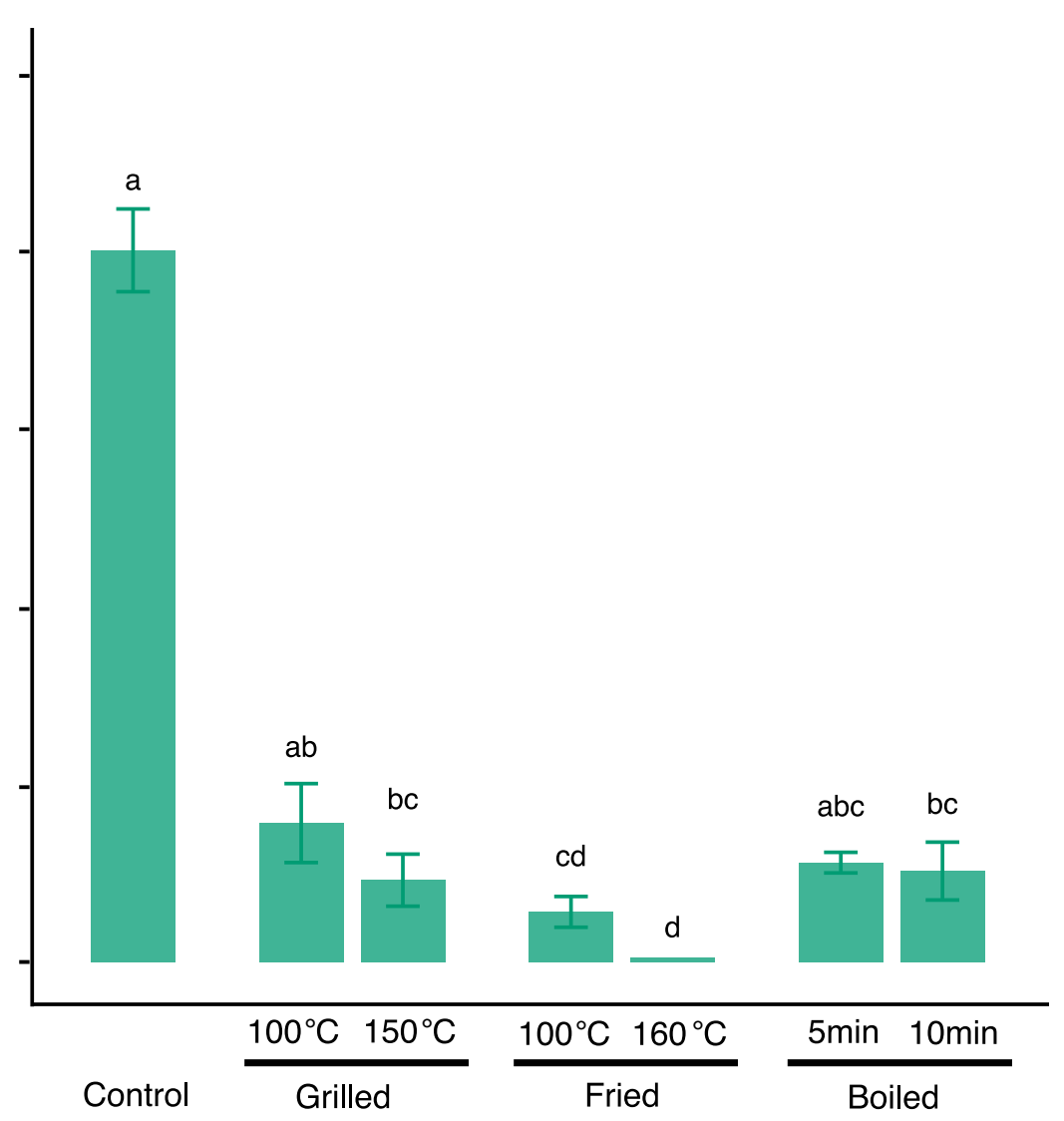


A.

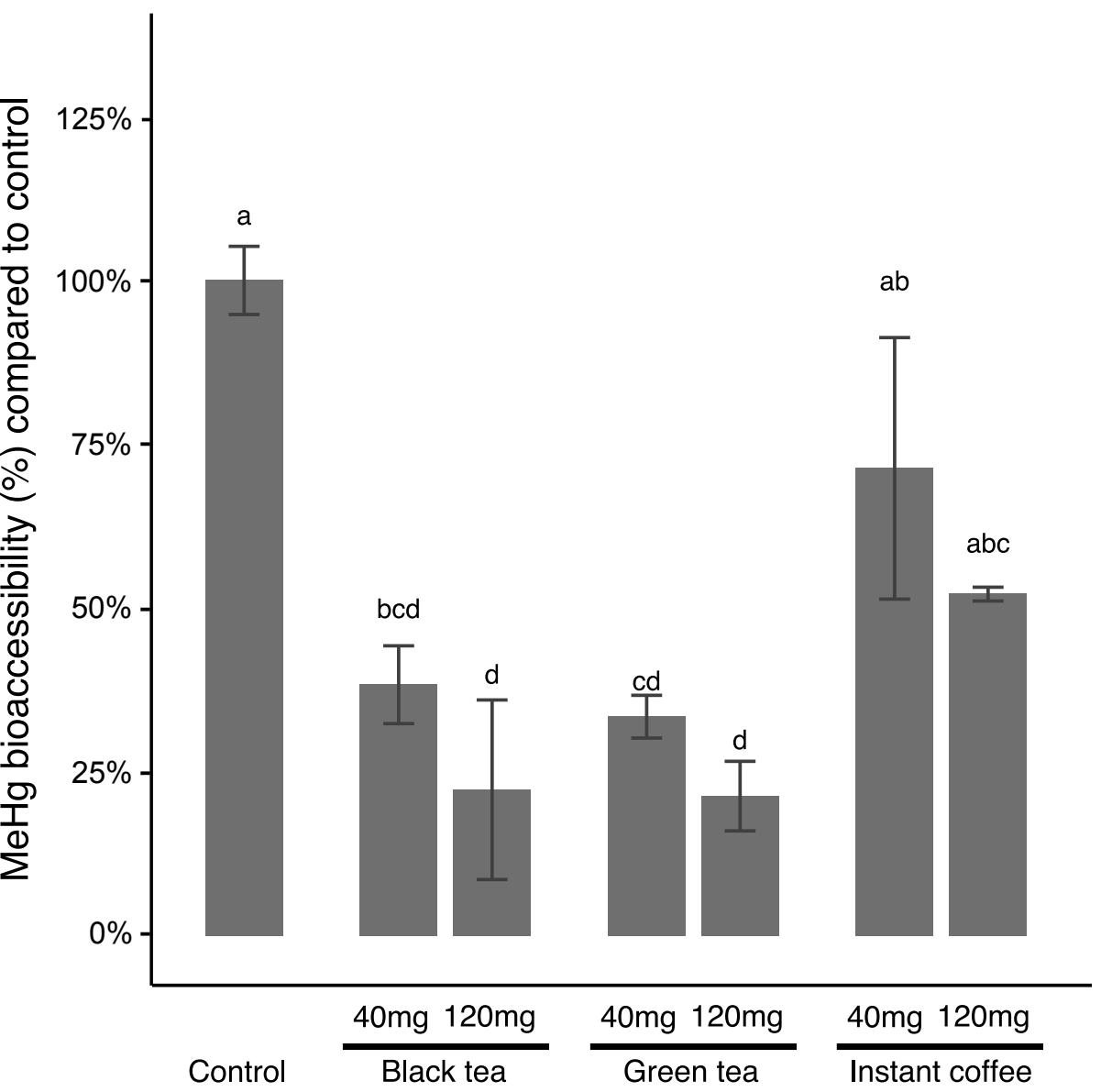

c.

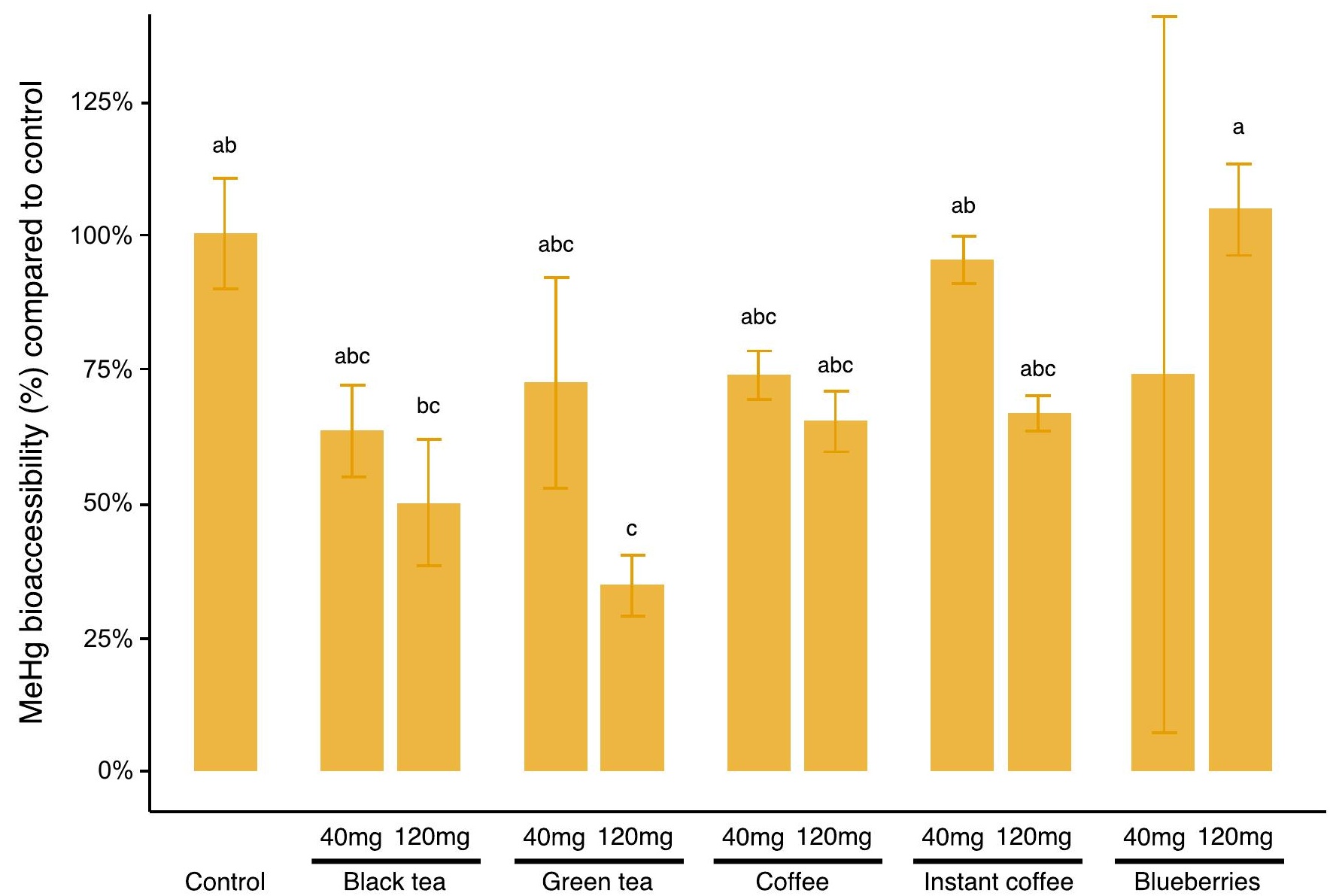

B.

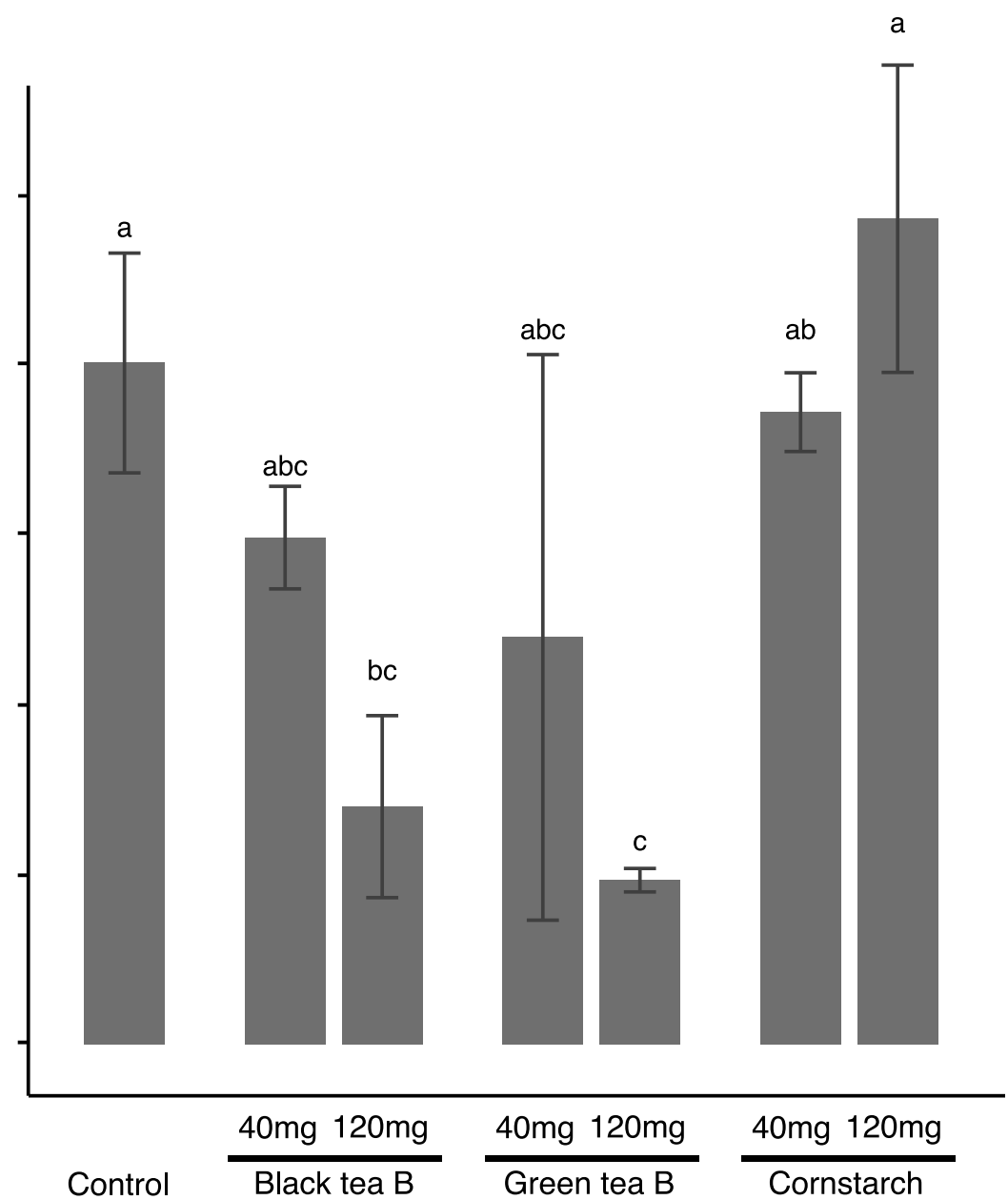

$a b c$ 
A.

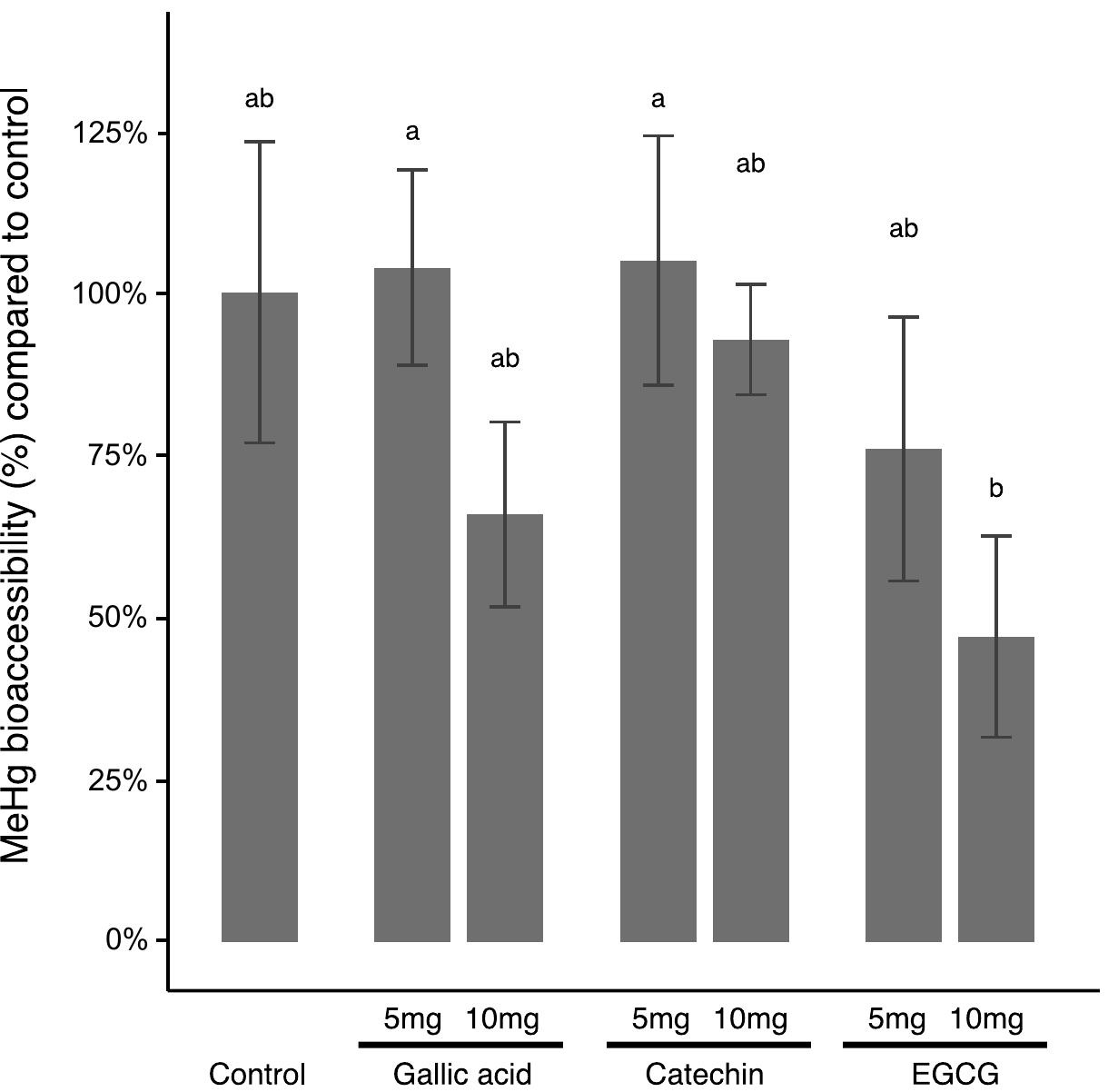

B.

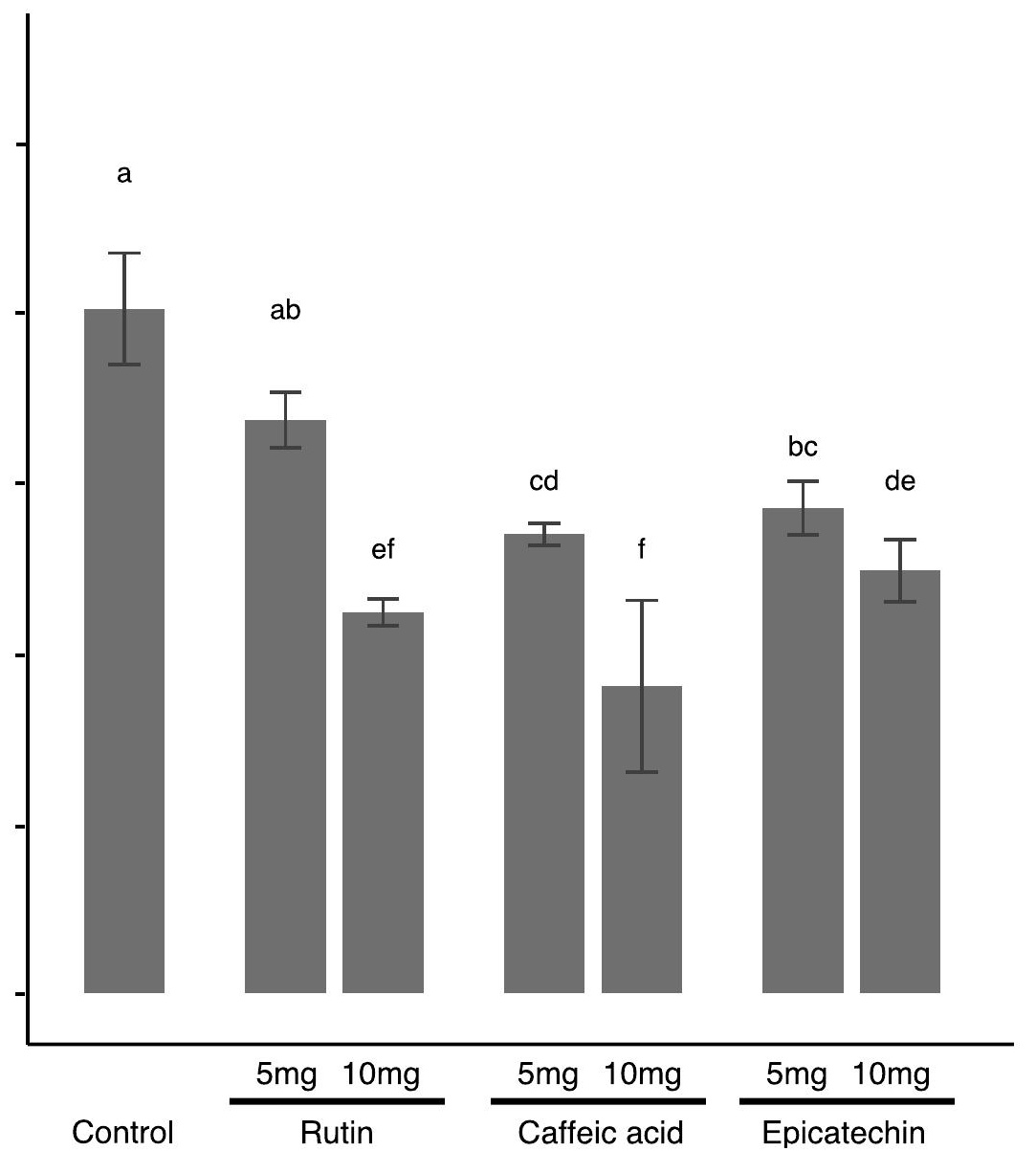


A.

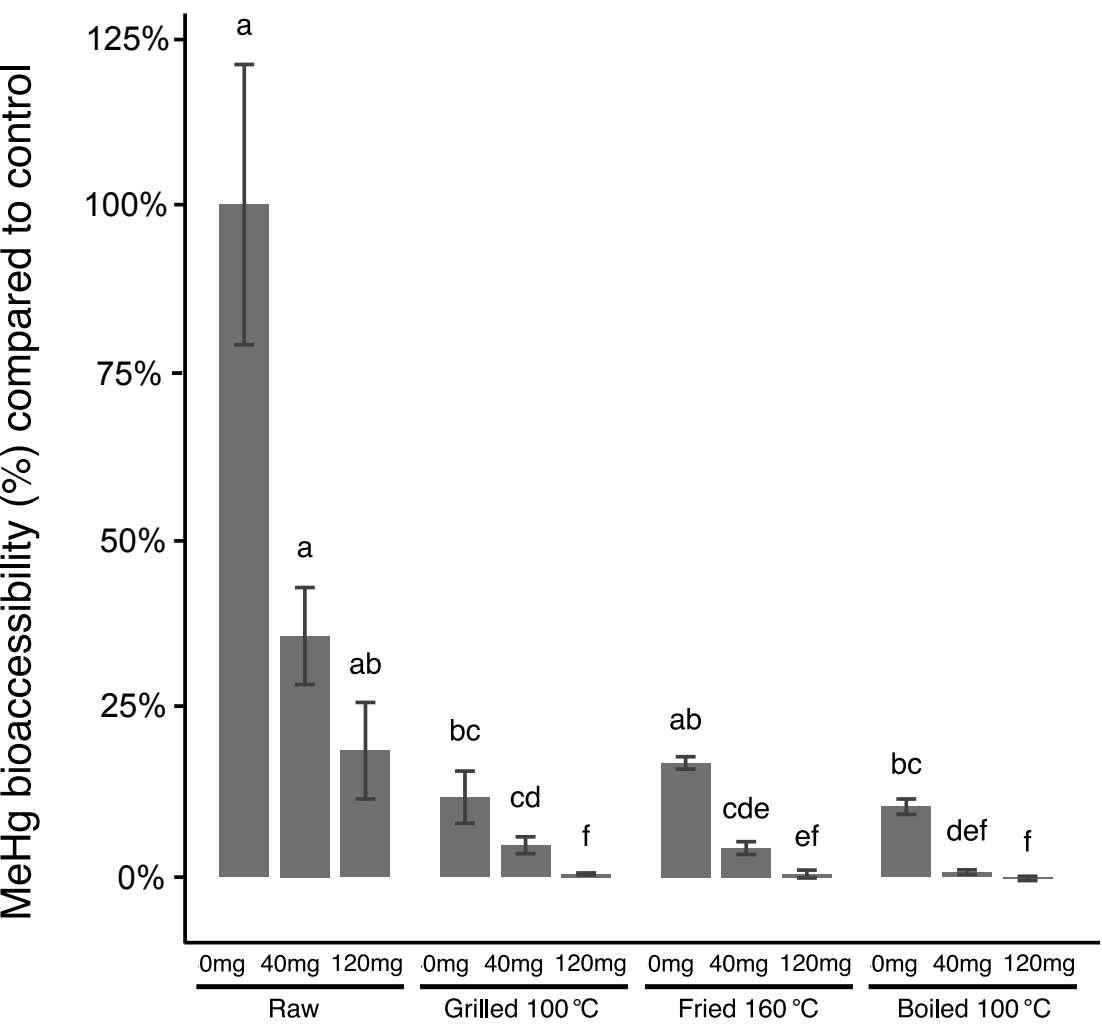

c.

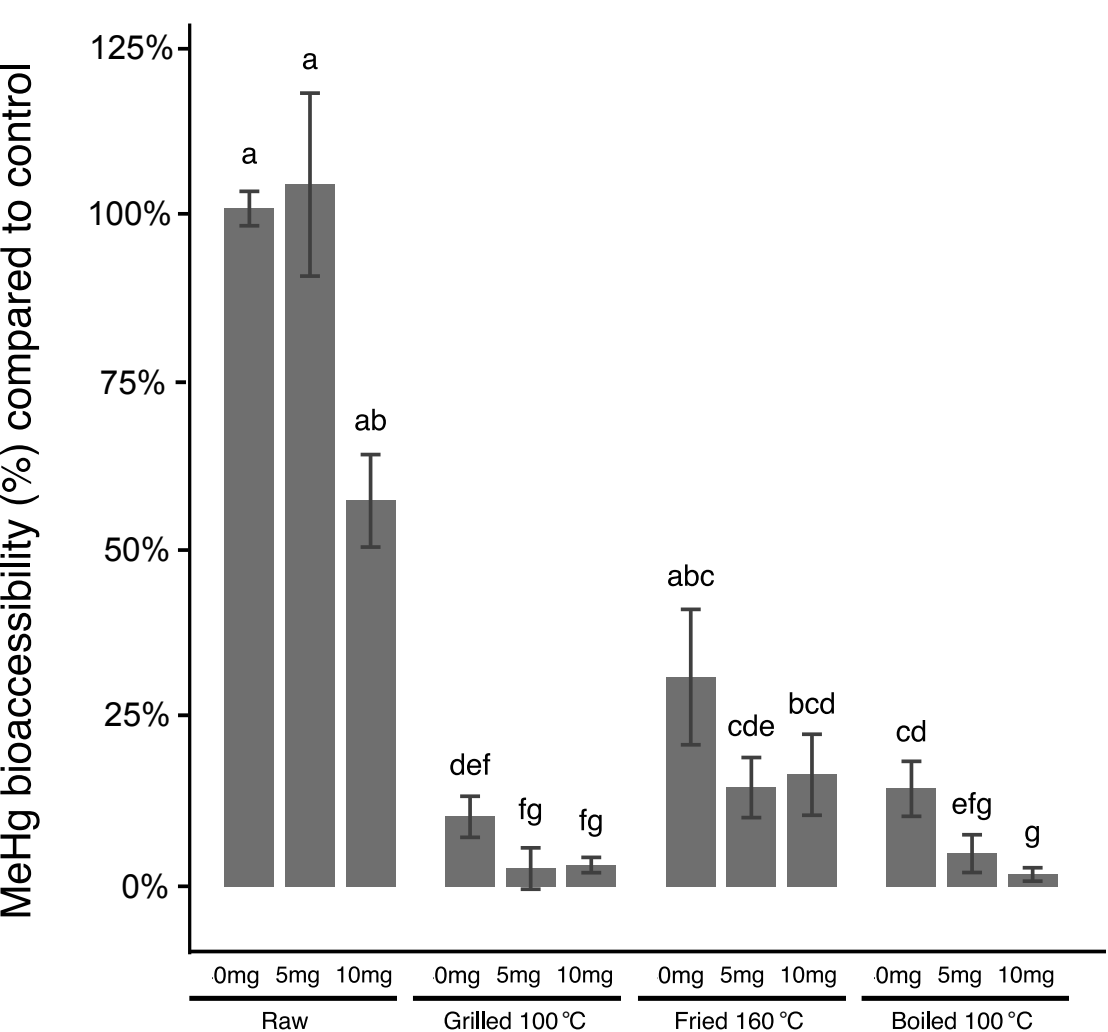

B.

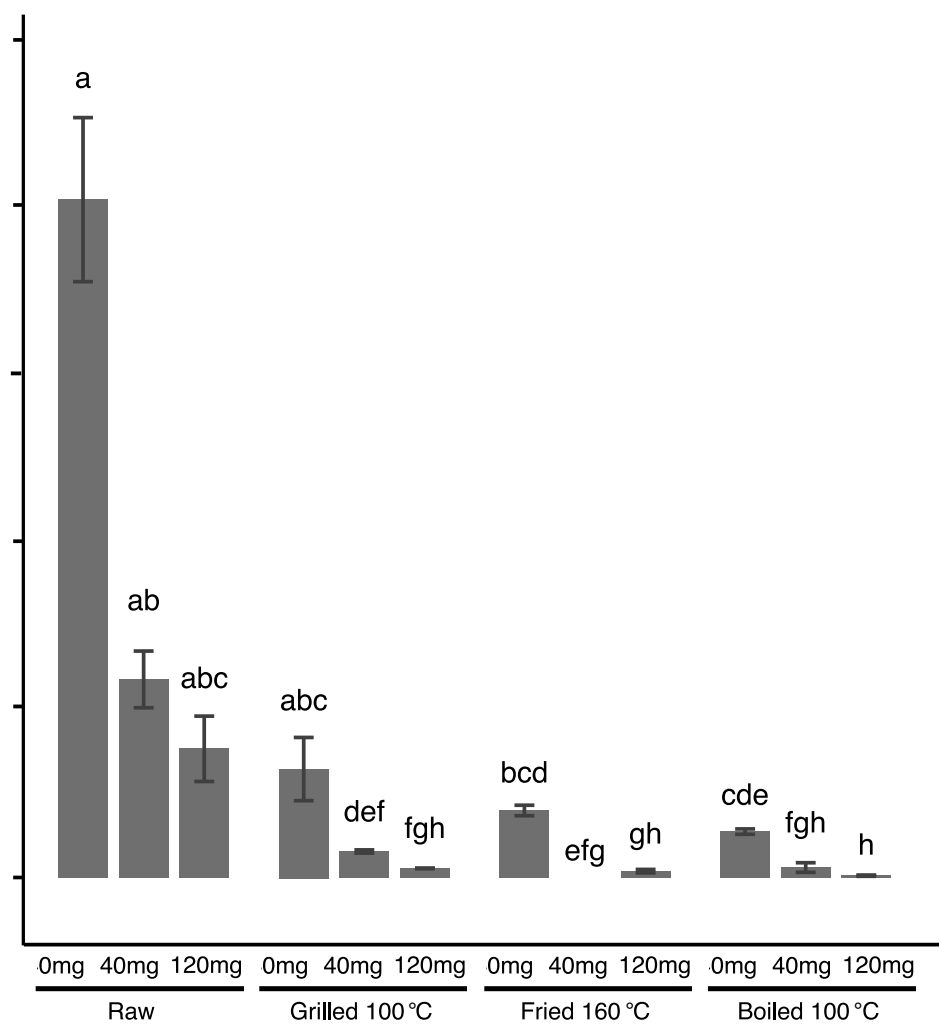

D.

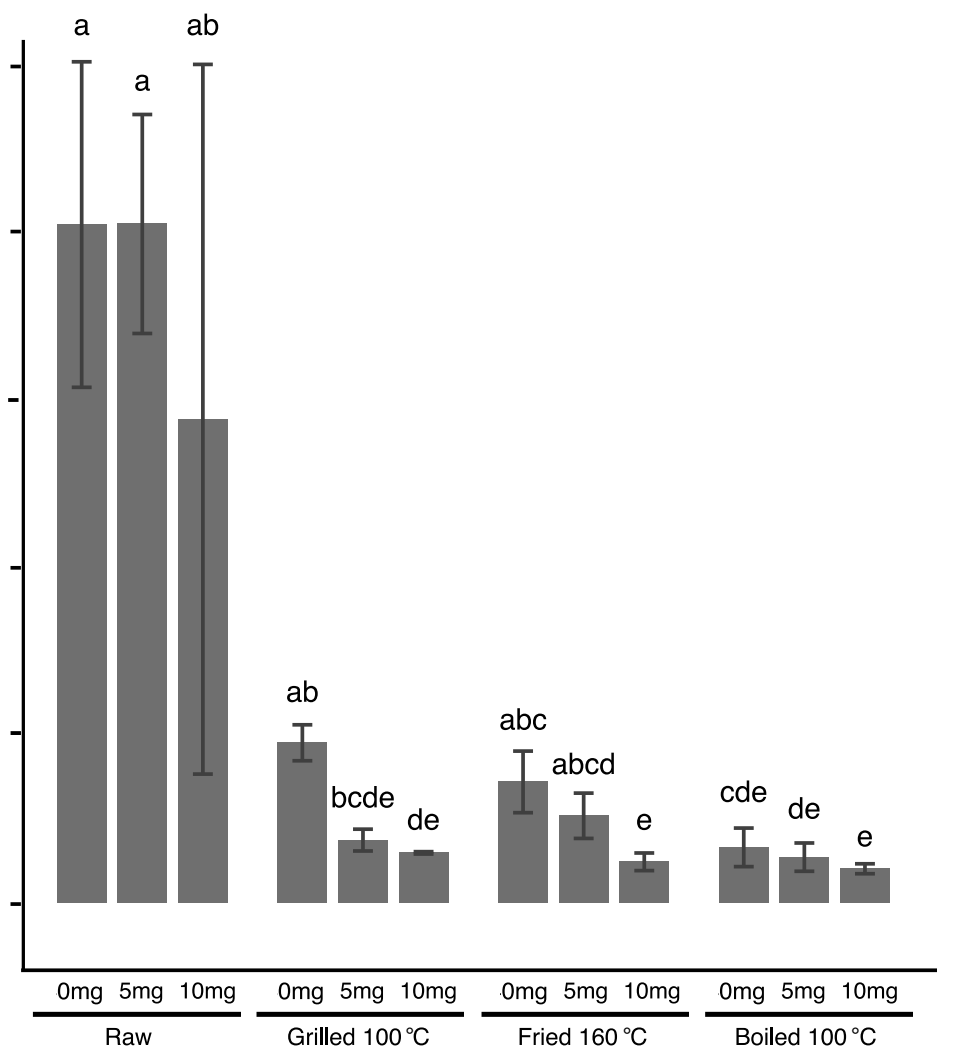




\section{Supplemental Material}

\section{Cooking and co-ingested polyphenols reduce in vitro methylmercury bioaccessibility from fish and may alter exposure in humans}

Catherine Girard (1), Tania Charette (2, 3), Maxime Leclerc (2, 3), B. Jesse Shapiro (3), Marc Amyot $(1,2,3)$

(1) Center for Northern Studies (CEN), Département de sciences biologiques, Université de Montréal, Montreal, Canada.

(2) ÉcoLac, Département de sciences biologiques, Université de Montréal, Montréal, Canada.

(3) Groupe de recherche interuniversitaire en limnologie et en environnement aquatique (GRIL), Département de sciences biologiques, Université de Montréal, Montreal, Canada.

\#Address correspondence to Marc Amyot, m.amyot@umontreal.ca

\section{Table of content}

Supplemental material contains supplementary methods, 4 supplementary tables (Tables S1S4) and 7 supplementary figures (Figures $\mathrm{S1}$-S7). 


\section{Supplementary Methods}

\section{MeHg analyses}

Calibration curves were prepared using certified $\mathrm{MeHg}$ solutions. In brief, a MeHg stock solution (1000 ppm, certified by Alfa Aesar) was diluted in methanol (Fished Scientific, HPLC grade) to prepare a $1 \mathrm{mg} \mathrm{L}^{-1} \mathrm{MeHg}$ solution. Intermediate working solutions (10.0 $\mathrm{mg} \mathrm{L}^{-1}, 600 \mathrm{ng}$ $\mathrm{L}^{-1}$ and $10 \mathrm{ng} \mathrm{L}^{-1}$ ) were freshly prepared in MilliQ water and preserved with $0.3 \%$ acetic acid (Fisher Scientific, ACS-pur) and 0.2\% HCl (EMD, Omni-trace ultra).

\section{Fish matrix characterization}

Lipids were quantified by gravimetry, using a method adapted from Folch et al. Briefly, 5 $\mathrm{mL}$ of a 2:1 chloroform:methanol solution (>99.8 and 99.9\%, Fisher Scientific) were added to a Falcon tube containing $0.5-1 \mathrm{~g}$ of lyophilized and grinded fish sample. Tubes were vortexed for 15 seconds, then left under a fumehood overnight. Samples were vortexed again for 15 seconds, and centrifuged for 5 minutes at 1,500 g. Supernatant was poured into pre-weighed aluminum vessels, the pellet was washed with 2:1 chloroform:methanol solution and centrifuged once more, and washing solution was added to the vessel. Solutions were air-dried under a fumehood overnight, and were weighed. Percent lipid content was obtained with the following equation:

\section{[Equation S1]}

$\%$ lipid content $=\frac{\text { mass of vessel with sample }(g) \text {-mass of empty vessel }(g)}{\text { mass of fish extracted }(g)}$

Nitrogen was used as a proxy for protein content, and was quantified using a $\mathrm{CHN}$ Element Analyzer 1108 (Thermo Fisher). Samples were weighed in tin capsules and then burnt in a combustion column at $1,040{ }^{\circ} \mathrm{C}$ and reduced in a reduction column at $650{ }^{\circ} \mathrm{C}$, converting nitrogen into $N_{2}$. $N_{2}$ was separated from other gases generated during reduction by gas chromatography, then quantified by a thermo-electric detector. Calibrations were performed with acetanilide. Atropine and sulfanilamide (Elemental Microanalysis Limited) were used as standards.

Moisture content in fish muscle was quantified by subtracting sample dry weight from wet weight after drying. 


\section{Polyphenol analyses}

Polyphenols were quantified by UPLC-MSMS using a Waters Acquity Ultra-Performance LC system with a quaternary pump system and an Acquity high-strength silica T3 column (120 $\mathrm{mm} \times 2.1 \mathrm{~mm}, 1.8 \mathrm{~mm}$ particle size) (Waters). The stationary phase was 100\% silica particles. Compounds were separated with a mobile phase of $0.2 \%$ acetic acid (eluent $A$ ) and acetonitrile (eluent $\mathrm{B}$ ), with a flow rate of $0.4 \mathrm{~mL} \mathrm{~min}^{-1}$. The gradient elution was as follows: initial $5 \% \mathrm{~B}, 5$ $20 \%$ B (0 - $4.5 \mathrm{~min})$, isocratic $20 \%$ B (4.50 - $6.45 \mathrm{~min}), 20-45 \%$ B (6.45 - $13.50 \mathrm{~min}), 45-100 \%$ $B(13.5-16.5 \mathrm{~min})$, isocratic $100 \% B(16.5-19.5 \mathrm{~min}), 100-5 \% B(19.5-19.52 \mathrm{~min})$, isocratic $5 \%$ B (19.52 - $22.5 \mathrm{~min}$ ). MS analyses were performed on a TQD mass spectrometer (Waters) with a Z-spray electrospray interface in negative mode, with data acquisition carried out by multiple reactions monitoring (MRM). Ionization source parameters were as follow: capillary voltage at $2.5 \mathrm{kV}$, source temperature at $140{ }^{\circ} \mathrm{C}$, cone gas flow rate of $80 \mathrm{~L} \mathrm{~h}^{-1}$, desolvation gas flow rate of $900 \mathrm{~L} \mathrm{~h}^{-1}$ and desolvation temperature of $350{ }^{\circ} \mathrm{C}$. Nitrogen $(>99 \%)$ was used as a nebulizing gas, and argon $(>99 \%)$ as a collision gas. Data acquisition was performed with MassLynx 4.1 software. Results were quantified as gallic acid equivalents, and detection limits were calculated at $0.9 \mathrm{ug} \mathrm{g}^{-1}$ using standard gallic acid.

\section{Supplementary References}

Folch, J.; Lees, M.; Sloane Stanley, G. H. A simple method for the isolation and purification of total lipides from animal tissues. Journal of Biological Chemistry 1957, 226 (1), 497-509. 


\section{Supplementary Tables}

Table S1. Composition of fish matrix tested in bioaccessibility experiments. Values are reported for an individual fish, which was used in numerous subsequent analyses. Means are shown with standard deviation, with range in brackets and number of individual fish per species $(n)$.

\begin{tabular}{|l|c|c|c|c|}
\hline \multicolumn{1}{|c|}{ Fish } & $\mathrm{MeHg}\left(\mathrm{ng} \mathrm{g}^{-1}\right)$ & Protein (\%) & Lipids (\%) & Moisture (\%) \\
\hline Swordfish & $439.20 \pm 237.47 \mathrm{ng} \mathrm{g}^{-1}$ & $86.35 \pm 3.41 \%$ & $11.85 \pm 2.36 \%$ & $70.06 \pm 1.18 \%$ \\
& $(152.48-679.8)$ & $(13.25-14.33)$ & $(8.79-14.89)$ & $(69.13-72.23)$ \\
& $n=4$ & $n=3$ & $n=4$ & $n=4$ \\
\hline Grouper & $612.42 \pm 315.32 \mathrm{ng} \mathrm{g}^{-1}$ & $86.35 \pm 0.36 \%$ & $8.55 \pm 1.20 \%$ & $64.43 \pm 20.35 \%$ \\
& $(389.45-835.39)$ & $(13.77-13.88)$ & $(6.40-9.09)$ & $(50.04-78.82)$ \\
& $n=2$ & $n=3$ & $n=2$ & $n=2$ \\
\hline Tuna & $694.00 \pm 777.80 \mathrm{ng} \mathrm{g}^{-1}$ & $87.42 \pm 0.34 \%$ & $10.05 \pm 0.13 \%$ & $60.66 \pm 11.88 \%$ \\
& $(144.01-1243.98)$ & $(13.93-14.04)$ & $(9.91-10.16)$ & $(52.26-69.06)$ \\
& $n=2$ & $n=3$ & $n=2$ & $n=2$ \\
\hline Salmon & $20.16 \mathrm{ng} \mathrm{g}^{-1}$ & $n / a$ & $26.54 \%$ & $70.00 \%$ \\
& $(-)$ & & $n=1$ & $(-)$ \\
& $n=1$ & & $n=1$ \\
\hline
\end{tabular}

Table S2. Polyphenol content in different beverages and foods used in MeHg bioaccessibility, measured by UPLC-MS/MS. Polyphenols presented here are those we subsequently tested in their purified form. EGCG: epigallocatechin gallate; ND: undetected (detection limit $=0.9 \mathrm{ug} \mathrm{g}^{-1}$ ).

\begin{tabular}{|l|c|c|c|c|c|c|c|}
\hline Food item & $\begin{array}{c}\text { Gallic acid } \\
\left(\mathrm{ug} \mathrm{g}^{-1}\right)\end{array}$ & $\begin{array}{c}\text { Catechin } \\
\left(\mathrm{ug} \mathrm{g}^{-1}\right)\end{array}$ & $\begin{array}{c}\text { Epicatechin } \\
\left(\mathrm{ug} \mathrm{g}^{-1}\right)\end{array}$ & $\begin{array}{c}\text { EGCG } \\
\left(\mathrm{ug} \mathrm{g}^{-1}\right)\end{array}$ & $\begin{array}{c}\text { Theaflavin } \\
\left(\mathrm{ug} \mathrm{g}^{-1}\right)\end{array}$ & $\begin{array}{c}\text { Rutin } \\
\left(\mathrm{ug} \mathrm{g}^{-1}\right)\end{array}$ & $\begin{array}{c}\text { Cafeic acid } \\
\left(\mathrm{ug} \mathrm{g}^{-1}\right)\end{array}$ \\
\hline Black tea A & 8218.01 & 1338.73 & 4428.45 & 17505.91 & 153.97 & 41138.98 & 58.21 \\
\hline Black tea B & 7892.87 & 1226.50 & 3816.15 & 25131.52 & 52.71 & 47043.56 & 104.86 \\
\hline Green tea A & 1431.36 & 1770.37 & 25154.20 & 96256.16 & 167.06 & 38485.35 & 30.29 \\
\hline Green tea B & 3376.76 & 2269.17 & 16921.85 & 110499.05 & 133.59 & 15277.43 & 75.13 \\
\hline Coffee & ND & ND & ND & ND & ND & ND & 331.34 \\
\hline Instant coffee & ND & ND & ND & ND & ND & ND & 497.10 \\
\hline Blueberries & 11.52 & 33.49 & ND & 84.35 & ND & 147.57 & 50.89 \\
\hline Cornstarch & ND & ND & ND & 31.31 & ND & ND & ND \\
\hline
\end{tabular}

Table S3. Raw polyphenol content in beverages and foods tested in bioaccessibility experiments, measured by UPLC-MS/MS.

SuppTableS3.xlsx is available at https://github.com/cgir/PBET MeHg 


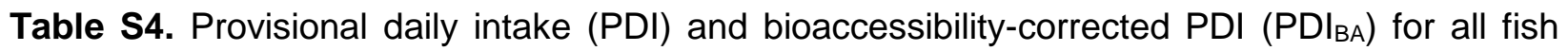
108 and treatments tested in this experiment.

\begin{tabular}{|c|c|c|c|c|c|c|c|c|}
\hline \multirow[b]{2}{*}{ Treatment } & \multicolumn{2}{|c|}{ Swordfish } & \multicolumn{2}{|c|}{ Grouper } & \multicolumn{2}{|c|}{ Tuna } & \multicolumn{2}{|c|}{ Salmon } \\
\hline & $\begin{array}{c}\text { PDI } \\
\mathrm{ug} \mathrm{kg}^{-1}\end{array}$ & $\begin{array}{l}\mathrm{PDI}_{\mathrm{BA}} \\
\mathrm{ug} \mathrm{kg}\end{array}$ & $\begin{array}{c}\mathrm{PDI} \\
\mathrm{ug} \mathrm{kg}^{-11}\end{array}$ & $\begin{array}{l}\mathrm{PDI}_{\mathrm{BA}} \\
\mathrm{ug} \mathrm{kg}^{-1}\end{array}$ & $\begin{array}{c}\text { PDI } \\
\mathrm{ug} \mathrm{kg}^{-1}\end{array}$ & $\begin{array}{l}\mathrm{PDI}_{\mathrm{BA}} \\
\mathrm{ug} \mathrm{kg}^{-1}\end{array}$ & $\begin{array}{c}\text { PDI } \\
\mathrm{ug} \mathrm{kg}^{-1}\end{array}$ & $\begin{array}{l}\mathrm{PDI}_{\mathrm{BA}} \\
\mathrm{ug} \mathrm{kg}\end{array}$ \\
\hline $\begin{array}{l}\text { Control (raw, unamended) } \\
\text { Grilling } \\
\text { Frying } \\
\text { Boiling }\end{array}$ & 0.126 & $\begin{array}{l}0.037 \\
0.007 \\
0.003 \\
0.003\end{array}$ & 0.143 & $\begin{array}{l}0.096 \\
0.012 \\
0.011 \\
0.023\end{array}$ & 0.053 & $\begin{array}{l}0.015 \\
0.002 \\
0.001 \\
0.002\end{array}$ & 0.007 & $\begin{array}{l}0.003 \\
<0.001 \\
<0.001 \\
<0.001\end{array}$ \\
\hline $\begin{array}{l}\text { Control (raw, unamended) } \\
\text { Green tea } \\
\text { Black tea }\end{array}$ & 0.126 & $\begin{array}{l}0.032 \\
0.007 \\
0.007\end{array}$ & 0.306 & $\begin{array}{l}0.072 \\
0.017 \\
0.025\end{array}$ & 0.456 & $\begin{array}{l}0.075 \\
0.026 \\
0.037\end{array}$ & - & $\begin{array}{l}- \\
-\end{array}$ \\
\hline $\begin{array}{l}\text { Control (raw, unamended } \\
\text { EGCG }\end{array}$ & 0.249 & $\begin{array}{l}0.084 \\
0.040\end{array}$ & - & - & - & $\begin{array}{l}- \\
-\end{array}$ & - & - \\
\hline $\begin{array}{l}\text { Control (raw, unamended) } \\
\text { Grilling + green tea }\end{array}$ & 0.126 & $\begin{array}{l}0.050 \\
0.001\end{array}$ & - & - & 0.456 & $\begin{array}{c}0.082 \\
<0.001\end{array}$ & - & $\begin{array}{l}- \\
-\end{array}$ \\
\hline
\end{tabular}




\section{Supplementary Figures}

\section{Figure S1}

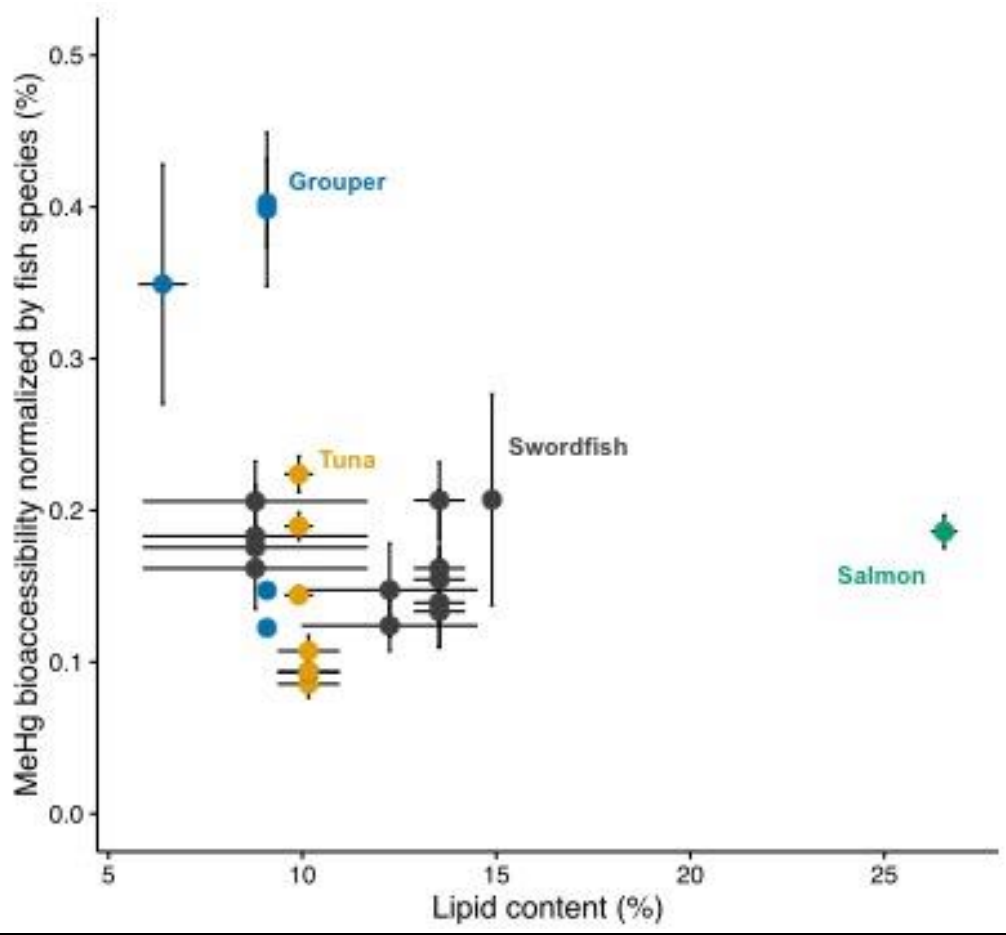

Supplementary Figure S1. MeHg bioaccessibility in relation to lipid content in different fish species (linear regression, $P>0.05$ ). Points present averages from individual fish, and error bars show standard deviation for lipid content (x-axis) and $\mathrm{MeHg}$ bioaccessibility (y-axis). 


\section{Figure S2}
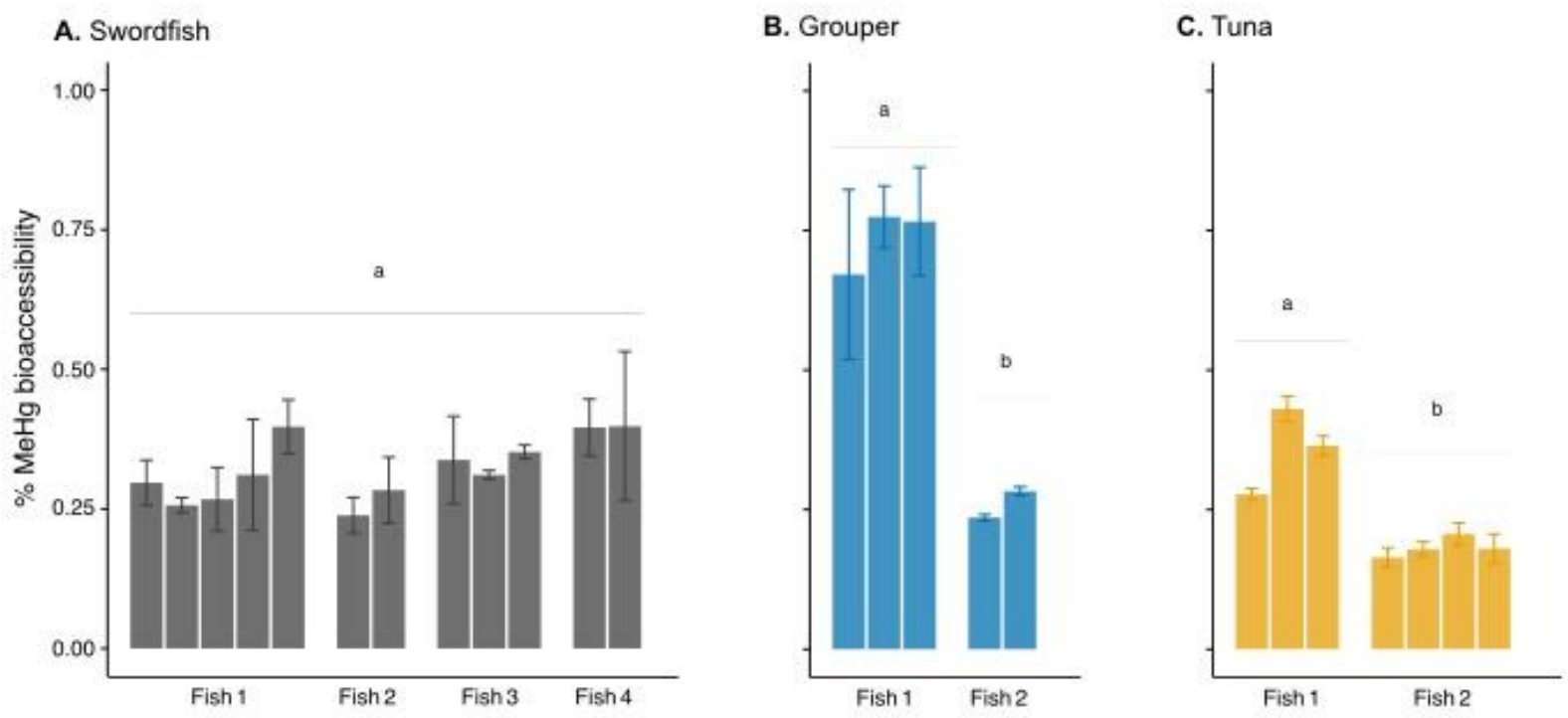

Supplementary Figure S2. MeHg bioaccessibility in raw fish from different individuals. Within a given individual, bioaccessibility did not vary significantly (Kruskal-Wallis, $P<0.05$ ). Letters denote significantly different treatments (Kruskal-Wallis, $P<0.05$ ) after Bonferonni multiple comparison correction, bars present averages from triplicate PBET digestions and error bars show standard deviation of triplicates. 


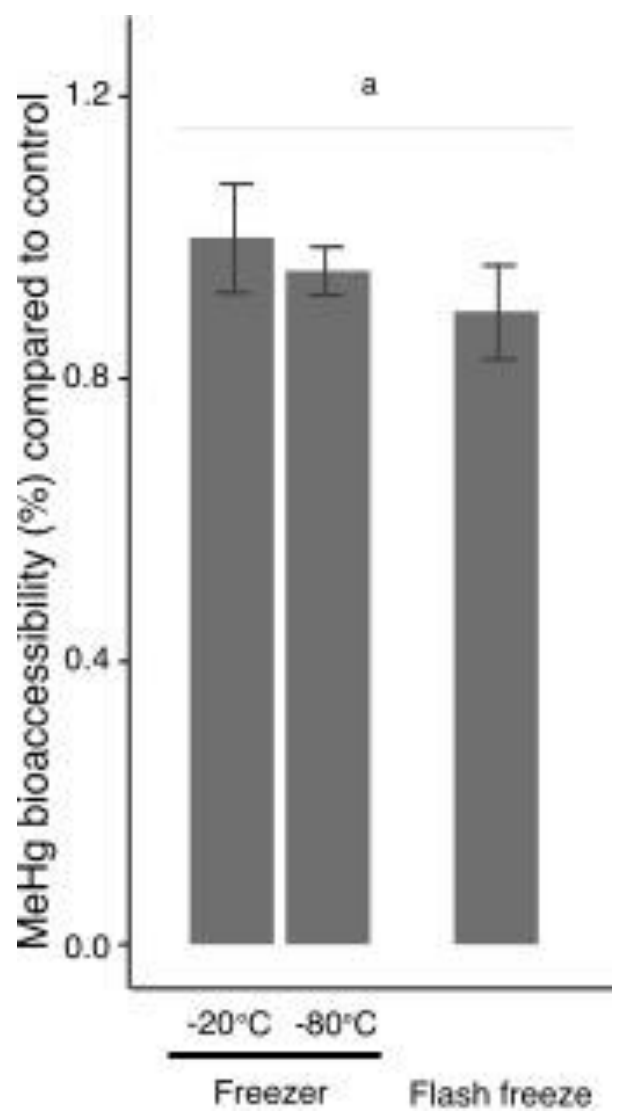

Supplementary Figure S3. Effect of freezing on MeHg bioaccessibility in swordfish. Letters denote significantly different treatments (Kruskal-Wallis, $P<0.05$ ) after Bonferonni multiple comparison correction, bars present averages from triplicate PBET digestions and error bars show standard deviation of triplicates. 


\section{Figure S4}

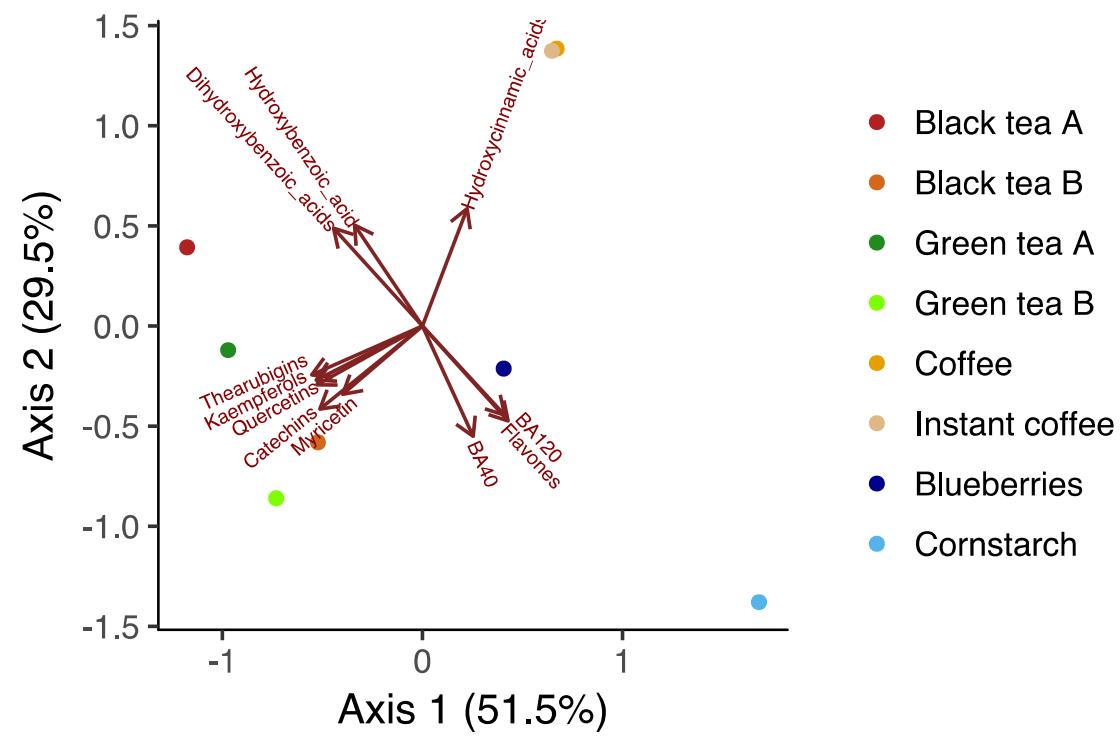

Supplementary Figure S4. Principal components analysis (PCA) correlation biplot showing bioaccessibility from experiments performed with polyphenol-rich treatments (colored points) and polyphenol content, broken down into 9 categories (red arrows). The PCA accounts for $81 \%$ of total variation from Axes 1 and 2. 
Figure S5

A.

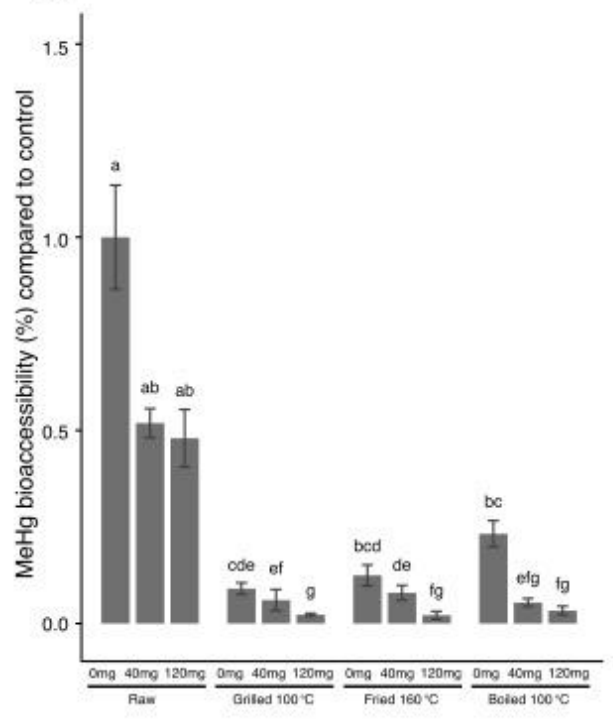

c.

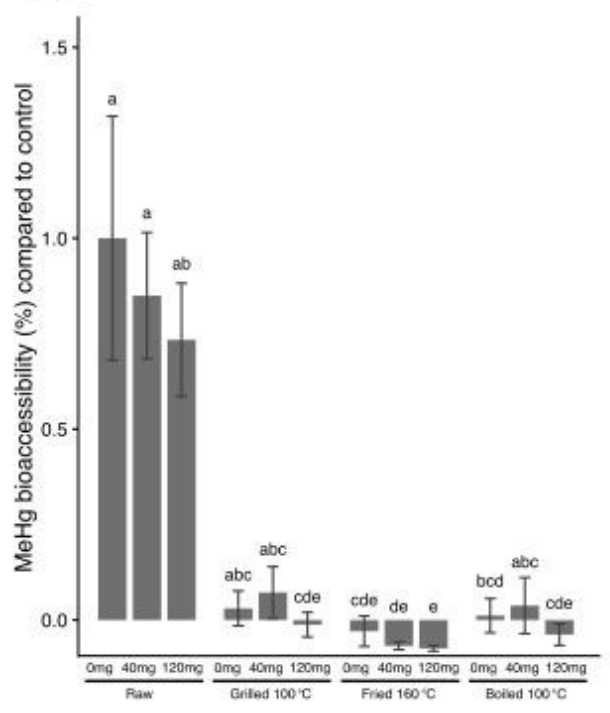

B.

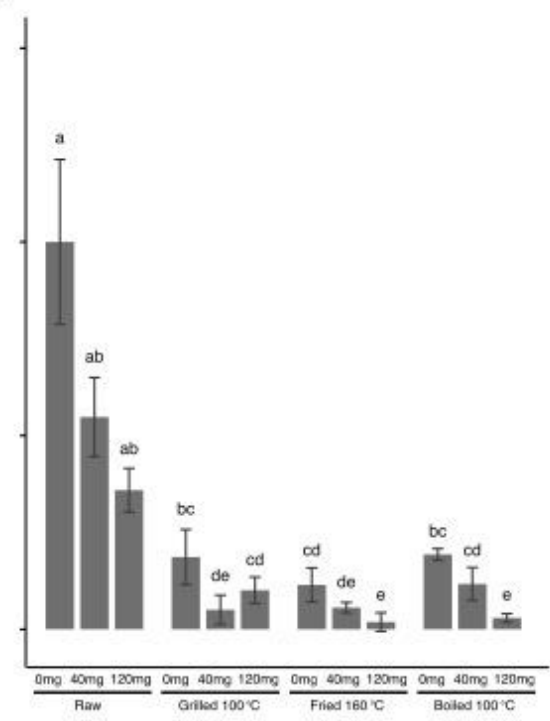

D.

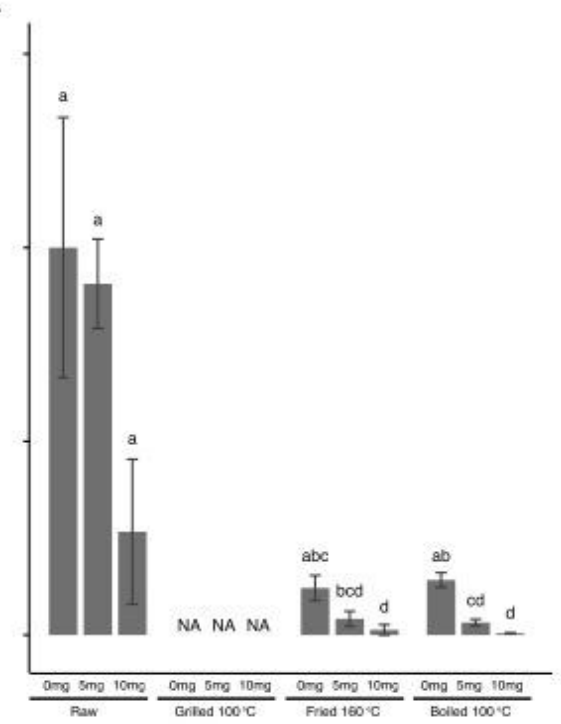

Supplementary Figure S5. Mixed effect of cooking and polyphenol/beverages on $\mathrm{MeHg}$ bioaccessibility in swordfish for polyphenol-rich beverages and foods (A. coffee, B. instant coffee and $\mathbf{C}$. blueberries) and for pure polyphenols (D. epigallocatechin gallate). Letters denote significantly different treatments (Kruskal-Wallis, $P<0.05$ ) after Bonferonni multiple comparison correction, bars present averages from triplicate PBET digestions and error bars show standard deviation of triplicates. 


\section{Figure S6}
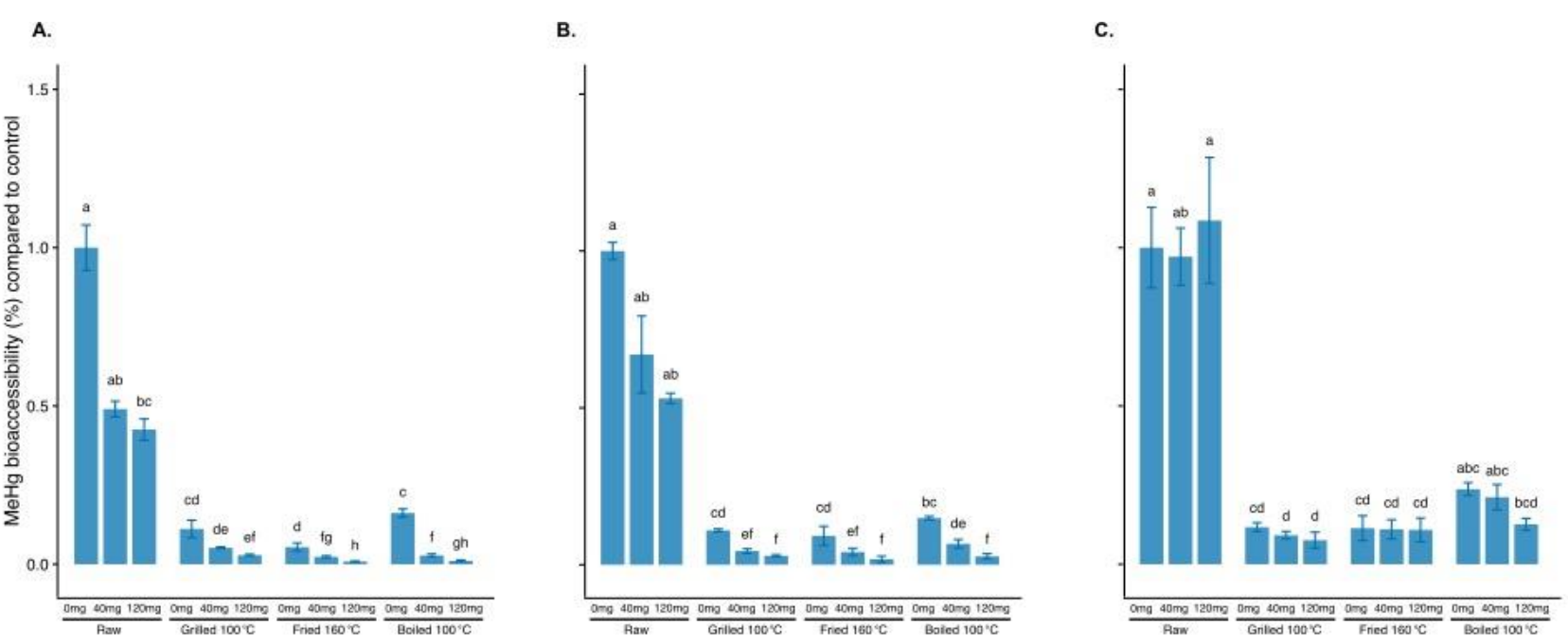

Supplementary Figure S6. Mixed effect of cooking and polyphenols/beverages on MeHg bioaccessibility in grouper. A. Coffee, B. instant coffee and C. blueberries. Letters denote significantly different treatments (Kruskal-Wallis, $P<0.05$ ) after Bonferonni multiple comparison correction, bars present averages from triplicate PBET digestions and error bars show standard deviation of triplicates. 
Figure S7
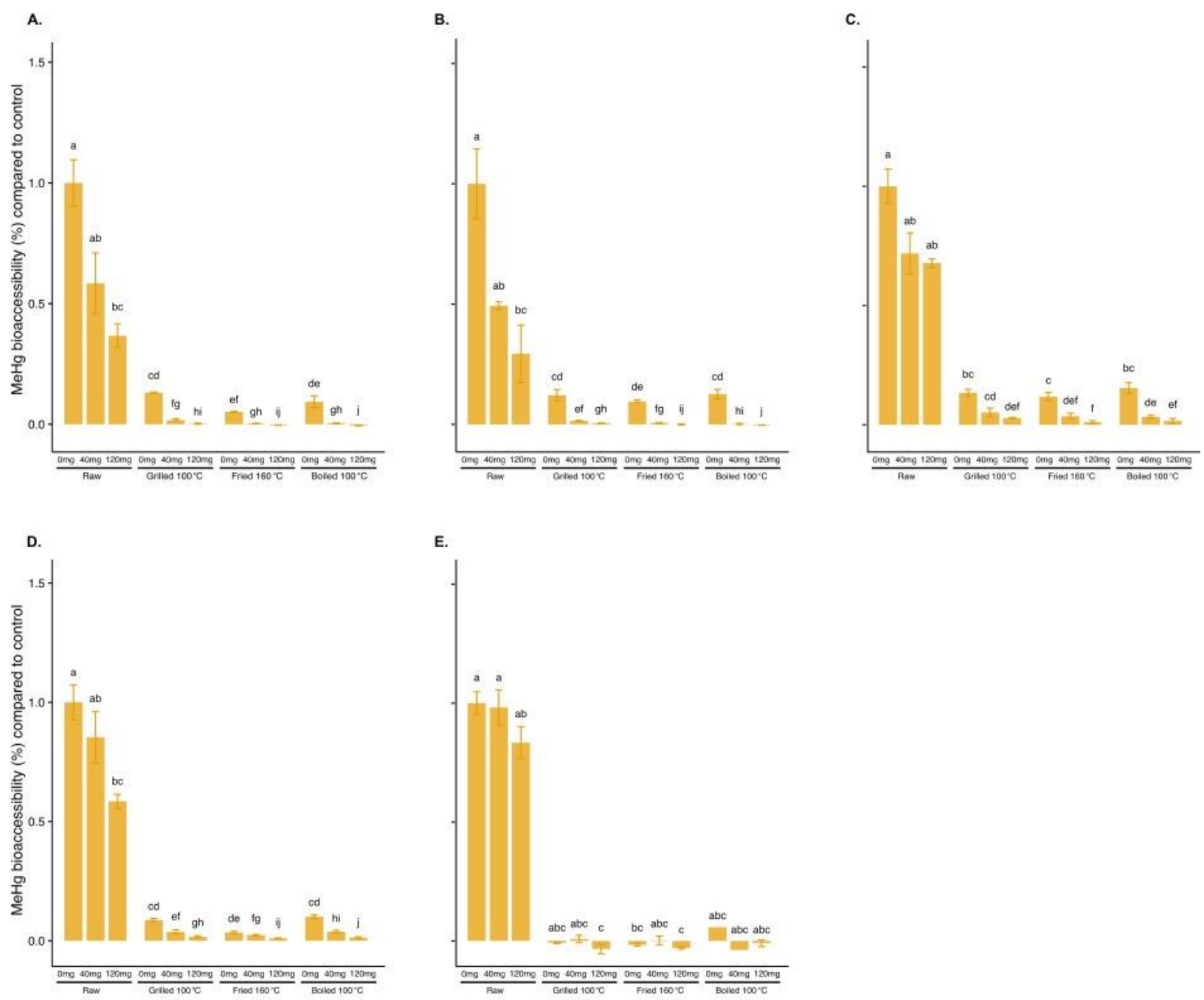

Supplementary Figure S7. Mixed effect of cooking and polyphenols/beverages on $\mathrm{MeHg}$ bioaccessibility in tuna. A. Black tea, B. green tea, C. coffee, D. instant coffee and E. blueberries. Letters denote significantly different treatments (Kruskal-Wallis, $P<0.05$ ) after Bonferonni multiple comparison correction, bars present averages from triplicate PBET digestions and error bars show standard deviation of triplicates. 